Article

\title{
Polydopamine Modified Superparamagnetic Iron Oxide Nanoparticles as Multifunctional Nanocarrier for Targeted Prostate Cancer Treatment
}

\author{
Nimisha Singh ${ }^{1}$, Fadoua Sallem ${ }^{2}$, Celine Mirjolet ${ }^{3}{ }^{\circledR}$, Thomas Nury ${ }^{4}$, Suban Kumar Sahoo ${ }^{1}$, \\ Nadine Millot ${ }^{2, *}$ and Rajender Kumar ${ }^{1, *}$ \\ 1 Department of Applied Chemistry, Sardar Vallabhbhai National Institute of Technology, 395007 Surat, India; \\ nimisha.singh01@gmail.com (N.S.); sks@chem.svnit.ac.in (S.K.S.) \\ 2 Laboratoire Interdisciplinaire Carnot de Bourgogne (ICB), UMR 6303 CNRS/Université Bourgogne \\ Franche-Comté, 21000 Dijon, France; fadouasallem@gmail.com \\ 3 Radiotherapy Department, Centre Georges-François Leclerc, 21000 Dijon, France; CMirjolet@cgfl.fr \\ 4 Laboratoire Bio-PeroxIL, Université Bourgogne Franche-Comté/Inserm, 21000 Dijon, France; \\ thomas.nury@u-bourgogne.fr \\ * Correspondence: nmillot@u-bourgogne.fr (N.M.); rajenderkumar@chem.svnit.ac.in (R.K.)
}

Received: 11 December 2018; Accepted: 12 January 2019; Published: 22 January 2019

\begin{abstract}
Polydopamine (pDA)-modified iron oxide core-shell nanoparticles (IONPs) are developed and designed as nanovectors of drugs. Reactive quinone of $\mathrm{pDA}$ enhances the binding efficiency of various biomolecules for targeted delivery. Glutathione disulfide (GSSG), an abundant thiol species in the cytoplasm, was immobilized on the pDA-IONP surface. It serves as a cellular trigger to release the drug from the nanoparticles providing an efficient platform for the drug delivery system. Additionally, GSSG on the surface was further modified to form S-nitrosoglutathione that can act as nitric oxide (NO) donors. These NPs were fully characterized using a transmission electronic microscopy (TEM), thermogravimetric analysis (TGA), dynamic light scattering (DLS), zeta potential, X-ray photoelectron spectroscopy (XPS), Fourier transform infrared (FTIR) and UV-vis spectroscopies. Doxorubicin (DOX) and docetaxel (DTX) are two anticancer drugs, which were loaded onto nanoparticles with respective loading efficiencies of 243 and $223 \mu \mathrm{mol} / \mathrm{g}$ of IONPs, calculated using TGA measurements. DOX release study, using UV-vis spectroscopy, showed a $\mathrm{pH}$ responsive behavior, making the elaborated nanocarrier a potential drug delivery system. (3-(4,5-dimethylthiazol-2-yl)-5-(3-carboxymethoxyphenyl)-2-(4-sulfophenyl) -2H-tetrazolium (MTS) and apoptosis assays were performed on PC3 cell lines to evaluate the efficiency of the developed nanocarriers. These nanoparticles thus can prove their worth in cancer treatment on account of their easy access to the site and release of drug in response to changes to internal parameters such as $\mathrm{pH}$, chemicals, etc.
\end{abstract}

Keywords: core-shell nanoparticles; biocompatible; drug delivery; anticancer

\section{Introduction}

Multifunctional nanohybrid systems offer several advantages for integrating functional nanocomponents into one entity to manifest different roles in cancer therapeutics. They provide an ideal platform to construct the nanostructure material that can be tuned to the required physical and chemical properties. Although new chemotherapeutic molecules have been continuously developed to treat cancer, medical advancement has failed to control the serious side effects caused by such compounds [1]. Thus, to address these issues and have a targeted anticancer treatment, efficient drug delivery carrier is required. Nano drug delivery carrier shows the potential of carrying the 
anticancer drug to the targeted site and delivering it according to the required pharmacology activity. Consequently, core shell nanoparticles have emerged as a promising nanocarrier for targeting tumor cells [2].

Uniform core shell nanoparticles systems, having a magnetic core with a functional shell, have been widely explored in protein separation, targeted drug delivery, magnetic resonance imaging, etc. [3-5]. Polydopamine (pDA) coated iron oxide nanoparticles (IONPs) are such a class of nanohybrids that have been developed with considerable interest as a multifunctional platform, thanks to their unique biocompatibility, enhanced magnetic resonance (MR) contrast and facile surface modification [6]. pDA is the polymerized structure of dopamine (DA) monomer that undergoes self-polymerization at alkaline $\mathrm{pH}$ giving both catechol and amine functional groups on the surface [7]. During the polymerization step, it results in the formation of a conformal and continuous coating layer on any substrate material via strong binding affinity of catechol functional groups. Moreover, this shell thickness can be potentially monitored by varying the reaction condition and the amount of DA in the medium [8].

Recent years have witnessed an exponential growth in research concerning advance functionalization and application of pDA-based nanohybrids in medical fields [9]. Thus, we chose pDA-coated IONPs for immobilizing glutathione disulfide (GSSG), which can serve as an efficient nanocarrier to carry doxorubicin (DOX) and docetaxel (DTX) for prostate cancer treatment. pDA is known to carry highly functional groups on the surface that allows the immobilization of biomolecules via Michael addition [9]. Immobilizing biomolecules on the pDA surface can increase the efficacy of drug release in the system [10].

It was reported that nanocarriers bearing reducible disulfide bonds can be easily cleaved with GSSG by thiol/disulfide exchange [11]. Glutathione in living cells exists in a redox equilibrium state between the disulfide (GSSG, oxidized form) and sulfhydryl (GSH, reduced form) where the change in the concentration of glutathione level marks the change in the oxidative stress caused by the tumor cells. Thus, the triggered release largely depends on the redox potential controlled by the oxidation and the reduction of glutathione (GSH/GSSG) [12] and, therefore, can attain the intracellular delivery of loaded drug [13], DNA [14], and siRNA for cancer therapeutics [15]. Thus, biocompatible nanohybrids with disulfide/thiol groups are of great interest in improving the drug delivery system.

Our objective is focused on immobilizing GSSG on pDA-IONPs to serve as a dual purpose towards prostate cancer treatment. Since GSH plays an important role in determining various cellular processes, it has also been reported that it can be a determining factor for the sensitivity of some tumors to several chemotherapeutic agents [16]. It may also turn out to be a successful biomarker for selecting tumors potentially responsive to chemotherapeutic regimens.

Thus, firstly, we chose GSSG to reduce its disulfide bond in order to have thiol groups on IONP's surface. These free thiol groups can serve as nitric oxide (NO) donors in the system by forming S-nitrosothiols (SNOs). SNOs possess the same physiological functions as NO, which include neurotransmission, hormone secretion and vasodilation in living bodies [17,18]. Additionally, NO has also emerged as antimicrobial agent [19] and has a tumoricidal factor [20] that makes it a promising pharmaceutical agent. Secondly, reduced GSSG (GSH) can carry DOX or DTX drugs for targeted prostate cancer cell treatment. While DOX has been widely used in the treatment of hematological and solid tumor malignancies, DTX is popularly used in the treatment of prostate cancers. Thus, in the present work we explored DOX activity in treating prostate cancer along with DTX. The details of the objective can be better understood with Scheme 1 . 


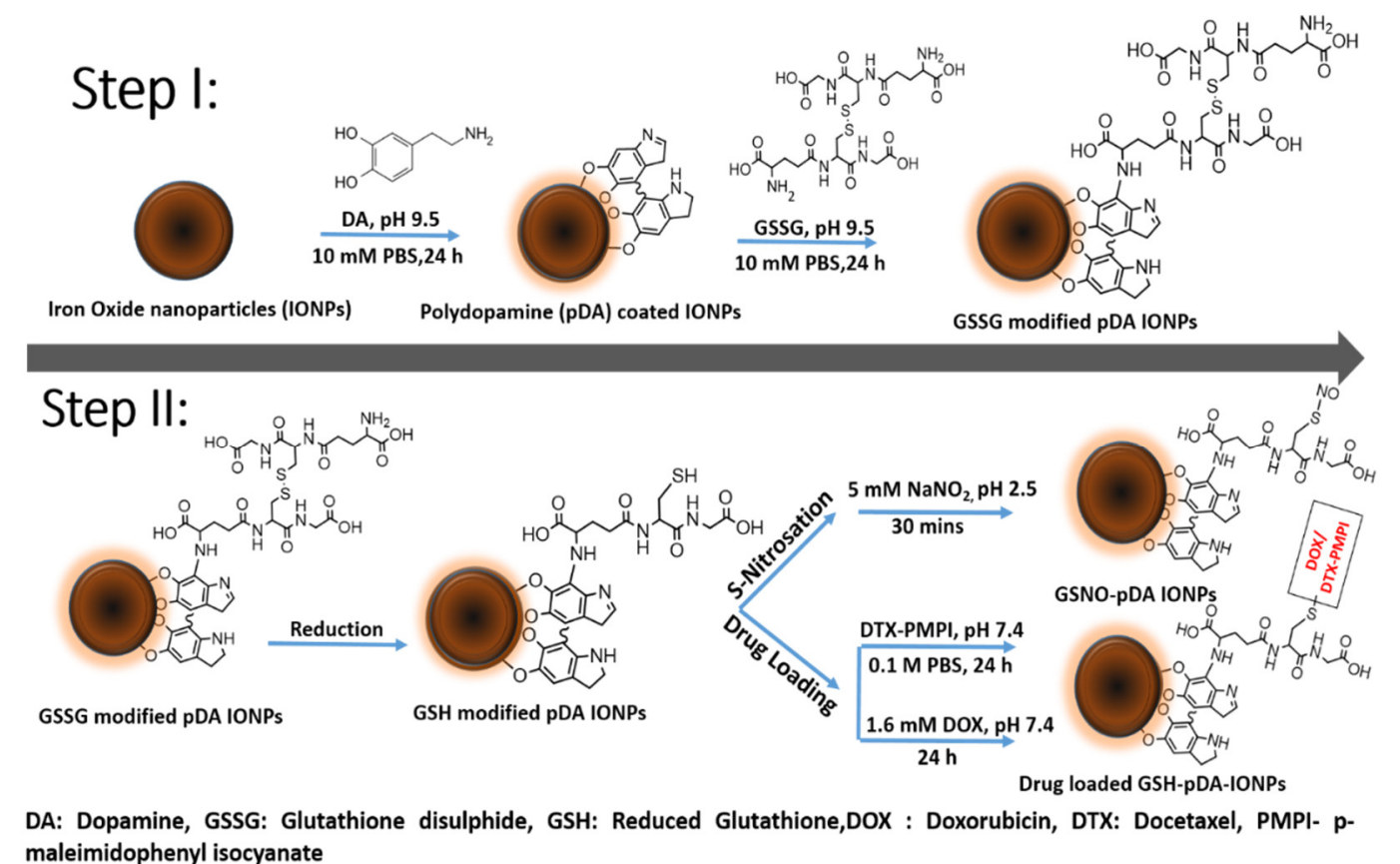

Scheme 1. Schematic representation showing the sequential synthesis of Step I: GSSG functionalized pDA-coated IONPs; and Step II: GSSG reduced to GSH-modified pDA-IONPs followed by S-nitrosation and loading of anticancer drugs (DOX and DTX).

\section{Materials and Methods}

Doxorubicin $\mathrm{HCl}(\mathrm{DOX})$, dopamine (DA), dithiothreitol (DTT), sodium hydroxide ( $\mathrm{NaOH}, \geq 97 \%)$, hydrochloric acid $(\mathrm{HCl}, 37 \%)$, nitric acid $\left(\mathrm{HNO}_{3}, 69 \%\right)$, Elman's reagent 5-dithiobis[2 nitrobenzoicacid] (DTNB) and ammonium hydroxide $\left(\mathrm{NH}_{4} \mathrm{OH}, 28 \%\right)$ were obtained from Sigma Aldrich (St. Louis, $\mathrm{MO}$, USA). p-maleimidophenyl isocyanate (PMPI) was purchased from Thermo Scientific (Fair Lown, NJ, USA). Iron (II) chloride tetrahydrate $\left(\mathrm{FeCl}_{2} \cdot 4 \mathrm{H}_{2} \mathrm{O}, 98 \%\right)$ and iron (III) chloride hexahydrate $\left(\mathrm{FeCl}_{3} \cdot 6 \mathrm{H}_{2} \mathrm{O}, 97 \%\right)$ were purchased from Alfa Aesar (Karlsruhe, Germany). Docetaxel (DTX) was purchased from BIOTREND Chemikalien GmbH (Cologne, Germany). PBS $1 \times$ solution (Fisher Bioreagents, Fair Lown, NJ, USA), and dimethyl sulfoxide (DMSO, $\geq 99.7 \%$ ) (Acroseal) were also purchased from Fisher Chemicals (Leicestershire, UK). Annexin V-FITC (fluorescein isothiocyanate) detection kit with PI (propidium iodide) staining for cell apoptosis was obtained from BD biosciences (Franklin Lakes, NJ, USA). Borate buffered saline was prepared from boric acid (99.8\%). Acetate buffer was prepared from sodium acetate and acetic acid. The ultrafiltration stirred cell (Model 8400, $400 \mathrm{~mL}$ ) and membranes (ref. \#PLHK07610, regenerated cellulose $100 \mathrm{kDa}$ ) were acquired from Merck Millipore (Darmstadt, Germany). All other chemicals were used of analytical grade and without further purification.

\subsection{Characterization Techniques}

The size and the morphology of the nanoparticles were analyzed using a JEOL JEM-2100 LaB6 transmission electronic microscope (TEM, Tokyo, Japan) with an acceleration voltage of $200 \mathrm{kV}$ and equipped with a high tilt pole-piece achieving a point-to point resolution of $0.25 \mathrm{~nm}$. The samples were prepared by evaporating a diluted suspension of NPs in deionized water on a carbon-coated copper grid. The average size of nanoparticles was determined by counting individual IONPs on each sample (150 nanoparticles).

The chemical composition of the NPs' surface, involved during the process of nanohybrid synthesis, was investigated with X-ray photoelectron spectroscopy (XPS) using PHI 5000 Versaprobe apparatus (ULVAC-PHI, Osaka, Japan) with a monochromatic Al K $\alpha 1$ X-ray source (energy of $1486.7 \mathrm{eV}$ with a $200 \mu \mathrm{m}$ spot size, accelerating voltage of $12 \mathrm{kV}$, and power of $200 \mathrm{~W}$ ). The applied pass energy 
(PE) was $180 \mathrm{eV}$ for the spectra and $50 \mathrm{eV}$ for windows. Powders were pressed on an indium sheet. Data were analyzed using CasaXPS software for processing the peaks. Neutralization was used to minimize charge effects and the carbon C1s peak at $284.5 \mathrm{eV}$ was used as the reference. A Shirley background was subtracted and Gauss (70\%)-Lorentz (30\%) profiles were used. Full width at half maximum (FWHM) was fixed between 1.5 and $1.9 \mathrm{eV}$. ULVAC-PHI MultiPak software (ver. 9.0.1, Osaka, Japan) was employed for quantitative analysis.

To confirm the functionalization of pDA and the immobilization of GSSG over the IONPs, a Bruker Vertex 70v (Billerica, MA, USA) using OPUS version 3.1 was used to obtain Fourier transform infrared (FT-IR) spectra using the KBr method with the wavenumber range of $400-4000 \mathrm{~cm}^{-1}$, resolution of $4 \mathrm{~cm}^{-1}$ and a total of 30 scans per measurement.

UV-visible spectroscopic measurements were carried out to study the absorbance of the as prepared nanoparticles and drug release kinetics using a Shimadzu UV-2550 UV-Vis spectrophotometer (Tokyo, Japan). All the spectra were measured in the range of 220-800 nm and recorded at room temperature using quartz cuvette of $1 \mathrm{~cm}$ path length.

Drug kinetics were also analyzed using fluorescence spectroscopy using a Cary Eclipse fluorescent spectrophotometer (Santa Clara, CA, USA) in the emission range of 380-700 $\mathrm{nm}$. The selected excitation and emission slits were 5 and $10 \mathrm{~nm}$, respectively.

Hydrodynamic diameter and zeta potential measurements were carried out using Malvern Nano ZS instrument (Worcestershire, UK) supplied by DTS Nano V7.11 software (Worcestershire, UK). The Smoluchowski equation was used for zetametry measurements. For each measurement, powders were dispersed in $12 \mathrm{~mL}$ of $\mathrm{NaCl}$ aqueous solution $\left(10^{-2} \mathrm{M}\right)$. $\mathrm{pH}$ titrations were performed using $\mathrm{HCl}(0.1 \mathrm{M}), \mathrm{NaOH}(0.1 \mathrm{M})$ or $\mathrm{NaOH}(0.01 \mathrm{M})$ aqueous solutions. Standard deviations were calculated from three measurements performed on the same sample. Samples were analyzed using a backscattering angle $\left(173^{\circ}\right)$. The refractive index of $\mathrm{Fe}_{3} \mathrm{O}_{4} \mathrm{NPs}$ is 2.42 and the absorption is equal to 0.029. Hydrodynamic diameters in this paper refer to the Z-average, which is the intensity weighted mean diameter derived from the cumulants analysis. Hydrodynamic diameter was determined by dynamic light scattering (DLS, Malvern, Worcestershire, UK) curves, which were derived from a number distribution calculation process.

The diffraction data were collected at room temperature, using a D8 Advance X-ray diffractometer (Vantack detector) (Billerica, MA, USA), in the $2 \theta$ range $10-100^{\circ}$. The $\mathrm{Cu} \mathrm{K}_{\alpha 1,2}$ radiations $\left(\lambda_{\alpha 1}=1.540598 \AA\right.$ and $\left.\lambda_{\alpha 2}=1.544426 \AA\right)$ were applied. The data analysis was carried out with Topas $^{\circledR}$ software (Billerica, MA, USA). Le Bail method was used to obtain lattice parameters and mean crystallite size. The phase identification was established by comparison of the diffraction patterns to the ICDD: The International Centre for Diffraction Data Powder Diffraction File Reference.

Powders were analyzed using a Discovery TGA-TA instrument (Newcastle, UK) with a gas (nitrogen:oxygen 80:20) flow rate of $25 \mathrm{~mL} \mathrm{~min}^{-1}$. The applied thermal program was as following: ramp 1 of $20{ }^{\circ} \mathrm{C} \cdot \mathrm{min}^{-1}$ from 25 to $100{ }^{\circ} \mathrm{C}$; isotherm at $100{ }^{\circ} \mathrm{C}$ for $30 \mathrm{~min}$ (to remove the remaining moisture) and ramp 2 of $5^{\circ} \mathrm{C} \cdot \mathrm{min}^{-1}$ from 100 to $800{ }^{\circ} \mathrm{C}$.

Magnetic susceptibility measurements were performed on a Bartington MS3 magneto-susceptometer (Witney, England) at $300 \mathrm{~K}$. A MS2G mono frequency sensor at $1.3 \mathrm{kHz}$ from Bartington (Oxford, England) was used for around $1 \mathrm{~mL}$ cells operated at $1.3 \mathrm{kHz}$.

\subsection{Preparation of Coated Iron Oxide Nanoparticles}

\subsubsection{Synthesis of Bare IONPs}

Iron oxide nanoparticles $\left(\mathrm{Fe}_{3} \mathrm{O}_{4}\right.$, IONPs) were prepared by a facile chemical co-precipitation method [21] where $\mathrm{FeCl}_{3} \cdot 6 \mathrm{H}_{2} \mathrm{O}(34.6 \mathrm{~g})$ and $\mathrm{FeCl}_{2} \cdot 4 \mathrm{H}_{2} \mathrm{O}(12.7 \mathrm{~g})$, in the molar ratio of 2:1, were dissolved in $1.5 \mathrm{~L}$ of water. Then, $\mathrm{Fe}_{3} \mathrm{O}_{4}$ nanoparticles were precipitated quickly by adding ammonia $(120 \mathrm{~mL}, 28 \%)$ in the solution at $22{ }^{\circ} \mathrm{C}$. The obtained black suspension was stirred for $2-3 \mathrm{~min}$. The obtained black precipitate was then magnetically decanted and washed thoroughly with deionized 
(DI) water until the solution reached $\mathrm{pH}$. The precipitate was then kept in nitric acid solution (1 $\mathrm{mM}$, $\mathrm{pH} 3)$ and dialyzed against nitric acid solution $(10 \mathrm{mM})$ for $48 \mathrm{~h}$. Dialyzed nanoparticles were then centrifuged for $15 \mathrm{~min}$ at 20,000 $\mathrm{G}$ with deceleration to obtain stable IONPs. The supernatant was then used for further characterizations and surface modification.

\subsubsection{Synthesis of Polydopamine-modified IONPs: pDA-IONPs}

A quantity of $100 \mathrm{mg}$ of $\mathrm{Fe}_{3} \mathrm{O}_{4}\left(10 \mathrm{mg} \mathrm{mL}^{-1}\right)$ was dispersed under continuous stirring in $25 \mathrm{~mL}$ of $10 \mathrm{mM}$ DA solution (PBS, $10 \mathrm{mM}, \mathrm{pH} 9.0$ ) for $24 \mathrm{~h}$ at $22{ }^{\circ} \mathrm{C}$. After, polydopamine-modified nanoparticles (pDA-IONPs) were magnetically decanted, washed thoroughly 5 times with ultrapure water using ultrafiltration to remove the non-reacted DA (ensured using UV), and further dispersed in water.

\subsubsection{Preparation of GSSG-modified Nanoparticles}

GSSG-modified nanoparticles were prepared using $20 \mathrm{mg}$ of pDA-IONPs, which were dispersed in $1 \mathrm{mg} \mathrm{mL}^{-1}$ GSSG solution (10 mM PBS, pH 9.4) for $24 \mathrm{~h}$ under continuous magnetic agitation (700 rpm) at $22{ }^{\circ} \mathrm{C}$. The GSSG-modified nanoparticles (GSSG-pDA-IONPs) were magnetically separated using magnetic syringe [22], washed with PBS buffer and checked with DTT to ensure the complete removal of unreacted GSSG. DTT reduces the unreacted disulfide, giving a yellow color solution indicating the presence of disulfide group. The resultant nanoparticles were then washed and re-dispersed in PBS.

The above nanoparticles were then reduced to glutathione to get free -SH. Briefly, GSSG modified nanoparticles $(800 \mu \mathrm{L}$ of the suspension) were first mixed with Tris buffer $(0.2 \mathrm{M}, \mathrm{pH} 9)$, after which, DTT $(0.01 \mathrm{M})$ was added and the reduction of disulfide was allowed to proceed for $1 \mathrm{~h}$ at $22{ }^{\circ} \mathrm{C}$. To ensure the reduction, DTNB $(0.01 \mathrm{M})$ in acetate buffer $(0.2 \mathrm{M}, \mathrm{pH} 5)$ was reacted with the sample and the absorbance was measured at $408 \mathrm{~nm}$.

S-nitrosation was then performed using $\mathrm{NaNO}_{2}(0.4 \mathrm{mM})$. The reaction took place when GSH-pDA-IONPs were successively added in $\mathrm{NaNO}_{2}$ solution at $37^{\circ} \mathrm{C}$ and $\mathrm{pH} 2.5$ for 30 min in the dark. UV-vis spectra were recorded to see the formation of S-nitrosation and the resultant nanoparticles were finally washed with PBS buffer and re-dispersed in PBS.

\subsection{Drug Loading}

For the incorporation of doxorubicin (DOX), the DOX solution $\left(600 \mu \mathrm{L}, 1 \mathrm{mg} \mathrm{mL}^{-1}\right)$ was added dropwise with stirring to an aqueous dispersion of GSH-pDA-IONPs ( $3 \mathrm{mg}$ of particles in $5 \mathrm{~mL}$ of water) at $22{ }^{\circ} \mathrm{C}$. Stirring was continued for $24 \mathrm{~h}$ to allow the partitioning of the drug into the nanoparticles. The absorbance of the supernatant was measured to determine the loading efficiency of the nanoparticles before and after the reaction. The obtained nanoparticles were then washed with deionized water (DI), magnetically separated using magnetic syringe and resuspended in DI water for further studies. Quantification and release kinetics of loaded drug were performed using UV-vis spectroscopy and TGA.

For the incorporation of docetaxel (DTX), DTX was first activated using PMPI, where prior to loading, DTX was initially dispersed in DMSO and mixed with PMPI (1:4 molar ratio) in borate buffer saline solution $(0.1 \mathrm{M}, \mathrm{pH} 8.5)$ for $24 \mathrm{~h}$ at $22{ }^{\circ} \mathrm{C}$ [23]. The resultant solution was then dialyzed against water to eliminate unreacted PMPI. DTX-PMPI was then analyzed using nuclear magnetic resonance NMR and infrared spectroscopy (FTIR), and loaded on GSH-pDA-IONPs in a reaction medium of PBS (0.1 M, pH 7.4) for $24 \mathrm{~h}$ at $22^{\circ} \mathrm{C}$. The developed nanoparticles were then magnetically washed, separated and freeze dried for further characterizations.

\subsection{Release Profile}

After purification of DOX-loaded nanoparticles, the dialysis tube filled with DOX-loaded nanoparticles suspension was transferred to a beaker containing $25 \mathrm{~mL}$ of phosphate buffer $(10 \mathrm{mM})$ to study the drug release at $37^{\circ} \mathrm{C}$ with continuous stirring at $100 \mathrm{rpm}$. To quantify the drug release, $2 \mathrm{~mL}$ of samples were analyzed at different time interval. The amount of released DOX was analyzed 
with a spectrophotometer at $485 \mathrm{~nm}$. The release was studied in 3 different $\mathrm{pH}(3.5,5.4$ and 7.4$)$ where it was adjusted with $\mathrm{HCl}$ and $\mathrm{NaOH}$. The experiments were performed in triplicate for all samples.

\subsection{In Vitro Assays}

Cytotoxicity was measured on PC-3 cell lines. The cells, at a concentration of 3000 cells/well, were seeded in 96-well plates and incubated at $37{ }^{\circ} \mathrm{C}$ in $190 \mu \mathrm{L}$ of drug-free culture medium (DMEM) with 10\% of fetal bovine serum for $24 \mathrm{~h}$ before treatment (when cells were at around $20 \%$ confluence). The cytotoxicity assays were performed using the following compounds: free drug (DOX or DTX), GSH-pDA-IONPs, and drug loaded GSH-pDA IONPs. Tumor cells were incubated ( $10 \mu \mathrm{L}$ of drug on $190 \mu \mathrm{L}$ of culture medium) with a range of equivalent drug concentrations. After $48 \mathrm{~h}$ incubation, cell viability was evaluated using MTS (3-(4,5-dimethylthiazol-2-yl)-5-(3-carboxymethoxyphenyl)-2-(4-sulfophenyl)-2H-tetrazolium) assay (Promega Corporation, Madison, WI, USA) according to Mirjolet et al. [24]. Experiments were performed 6 times and the results were calculated as the mean of the measurements.

\subsection{Analysis of Cell Proliferation by Flow Cytometry}

Flow cytometry was used to analyze cells' proliferation after their incubation with a DOX-loaded sample, by estimating the proportion of cells in apoptosis. After $24 \mathrm{~h}$ of incubation in 6-well plates, PC-3 cells were exposed to GSH-pDA-IONPs and DOX-GSH-pDA-IONPs for $24 \mathrm{~h}$ plus a negative control well. After the treatment, a double staining with annexin V-FITC and propidium iodide (PI) was performed with an FITC annexin V apoptosis detection kit obtained from Thermo Scientific (Fair Lown, NJ, USA). The cells were washed twice in PBS without $\mathrm{Ca}^{2+}$ and $\mathrm{Mg}^{2+}$, trypsinized with $1 \mathrm{~mL}$ of trypsine solution $1 \times$ and then centrifuged for $5 \mathrm{~min}$ at $300 \mathrm{~g}$. After 2 washes with cold PBS, $1 \mathrm{~mL}$ of annexin V binding buffer $(1 \times), 10 \mu \mathrm{L}$ of annexin V-FITC and $10 \mu \mathrm{L}$ of PI staining solutions were added to each sample. Finally, cells were incubated for $15 \mathrm{~min}$ at $37^{\circ} \mathrm{C}$. Cell suspensions were analyzed with a Galaxy flow cytometer (Partec, Görlitz, Germany). Red fluorescence of PI was collected through a 590-nm long-pass filter and green fluorescence was collected through a 520-nm band-pass filter. For each sample, about 10,000 cells were analyzed and the data were treated with FlowJo (Tree Star Inc., Ashland, OR, USA) software.

\section{Results}

The morphology and the size of the synthesized nanoparticles were analyzed using TEM, XRD and DLS measurements as shown in Figure 1, where the size of bare IONPs is calculated to be $9.0 \pm 4.0 \mathrm{~nm}$ from TEM measurements and $10.1 \pm 0.1 \mathrm{~nm}$ from XRD (Figure S1). The lattice parameter determined from XRD is $8.368 \pm 0.001 \AA$. The diffracting planes (222), (311), (422) and (511) and the interatomic distances observed on the selected area diffraction pattern of $\mathrm{Fe}_{3} \mathrm{O}_{4}$ (Figures S1 and S2) are in good agreement with the spinel structure (ICDD: 19-0629) [25]. This lattice parameter suggests that the powder is slightly oxidized $\left(\mathrm{Fe}_{3} \mathrm{O}_{4}\right.$ crystallites and a small presence of $\gamma-\mathrm{Fe}_{2} \mathrm{O}_{3}$ on the surface) [26,27]. Additionally, with DLS measurements, the hydrodynamic diameter of IONPs at $\mathrm{pH}$ 5.0-6.0, is observed to be $33 \pm 5 \mathrm{~nm}$ (PDI $=0.38 \pm 0.07$ ). The TEM image of the polydopamine coated IONPs (Figure 1B) reveals the presence of a homogeneous layer of $\mathrm{pDA}$ on the surface with a thickness of about $2 \mathrm{~nm}$, calculated using ImageJ software. It is also observed that even with pDA coating, the crystalline nature of IONPs is retained (inset Figure 1B and Figure S2).

The hydrodynamic diameter, obtained from DLS measurements, is $164 \pm 8 \mathrm{~nm}$ (PDI $=0.66 \pm 0.01$ ) in the case of pDA-IONPs, which is larger than that of bare IONPs. Indeed, pDA form an organic shell with reactive functional groups, which increases the interaction between IONPs and forms small aggregates. This large size can be due to the swelling effect of the polymer when coated over IONPs [28]. During the polymerization step of dopamine, it tends to produce oligomers having from four to eight 5,6-dihydroxyindole units which are assembled in an orderly manner via $\pi$ stacking to 
form nanoaggregates [29]. This results in the formation of continuous film on the surface that can be seen in the TEM image (Figure 1B).
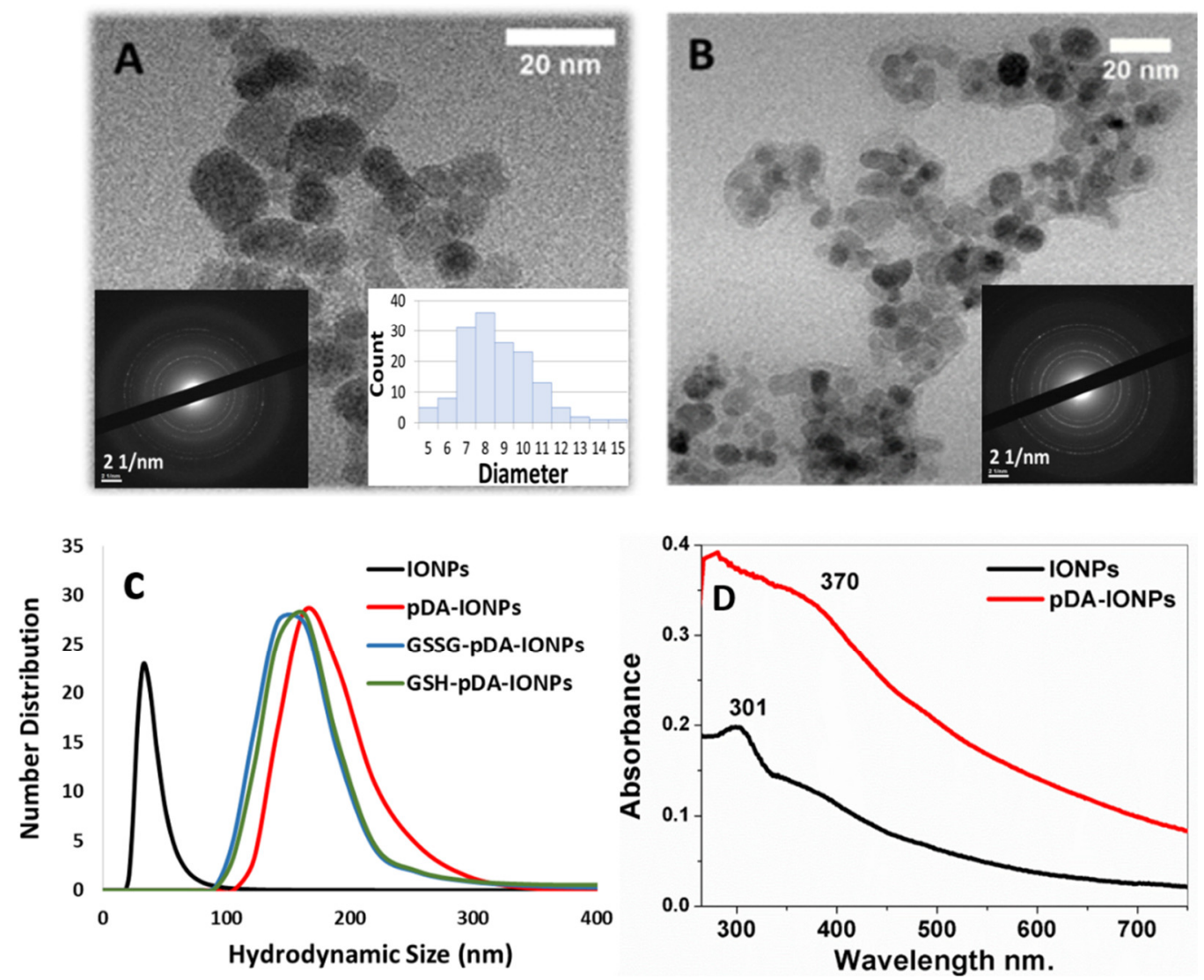

Figure 1. Transmission electronic microscope (TEM) images of (A) bare IONPs; and (B) pDA-coated IONPs (inset selected area (electron) diffraction (SAED) patterns and size distribution); (C) Dynamic light scattering (DLS) measurements showing the hydrodynamic diameter at $\mathrm{pH}=5.0-6.0$ and in $10^{-2} \mathrm{M} \mathrm{NaCl}$; and (D) UV-vis spectra of the synthesized nanoparticles.

UV-vis absorbance spectra are recorded to understand the polymerization step of DA on the surface of IONPs. In Figure 1D, the pDA-IONPs show an absorbance band at $370 \mathrm{~nm}$, which is the characteristic of polymerized layer of quinone, the intermediate molecule of $\mathrm{pDA}$, onto the IONP surface [21]. On the other hand, the characteristic absorbance band of IONPs is observed at $301 \mathrm{~nm}$ as shown in Figure 1D.

Since our objective is to have thiol groups on the surface for a wide range of applicability of the developed nanoparticles in the field of medicine, upon binding of GSSG to pDA-IONPs, similar hydrodynamic size $(141 \pm 2 \mathrm{~nm}$, PDI $=0.68 \pm 0.15)$ is observed. After the reduction of GSSG to GSH, the DLS measurements indicate the same hydrodynamic size as the previous step $(140 \pm 2 \mathrm{~nm}$, polydispersity index $(\mathrm{PDI})=0.33 \pm 0.03$ ). This result shows that reduction step does not affect the hydrodynamic size of coated IONPs.

It has been reported that physicochemical properties such as shape, size and surface charge mark an important role in the cellular uptake of nanoparticles [30]. Indeed, nanoparticles with a negative surface charge show greater cellular uptake due to their high interaction with cells or organs such as the liver [31]. Thus, zeta potential measurements were used to explore the surface charge of coated IONPs. The zeta potential of the synthesized nanoparticles with and without the surface modification with pDA and GSSG as a function of $\mathrm{pH}$ is measured as shown in Figure 2. The hydroxyl groups (Fe-OH) on the surface of bare IONPs are responsible for their surface charge. Indeed, in basic condition, it results in negative values of zeta potential due to the formation of $\mathrm{Fe}_{-} \mathrm{O}^{-}$and positive values in 
acidic conditions due to the formation of $\mathrm{Fe}-\mathrm{OH}_{2}{ }^{+}$[32]. The isoelectric point (IEP) of bare IONPs is measured to be 8.2 which decreases to $6.4,4.7$ and 4.5 upon functionalization with pDA, GSSG and GSH respectively. This shift in the IEP from 8.2 for bare IONPs to 4.5 for GSH-pDA-IONPs suggests the successful immobilization of GSH molecules onto the surface of IONPs [33]. Moreover, the decrease in the zeta potential values, after pDA and GSH grafting, proves the presence of an organic shell which hides a part of the surface charge of IONPs [34]. Also, at physiological pH, the colloidal stability of the synthesized nanoparticles, on the successive molecules' conjugation, is improved as shown in Figure S3, thanks to the increase in the absolute value of zeta potential and the steric hindrance of the organic molecules, thereby making them suitable nanocarriers for drug loading.

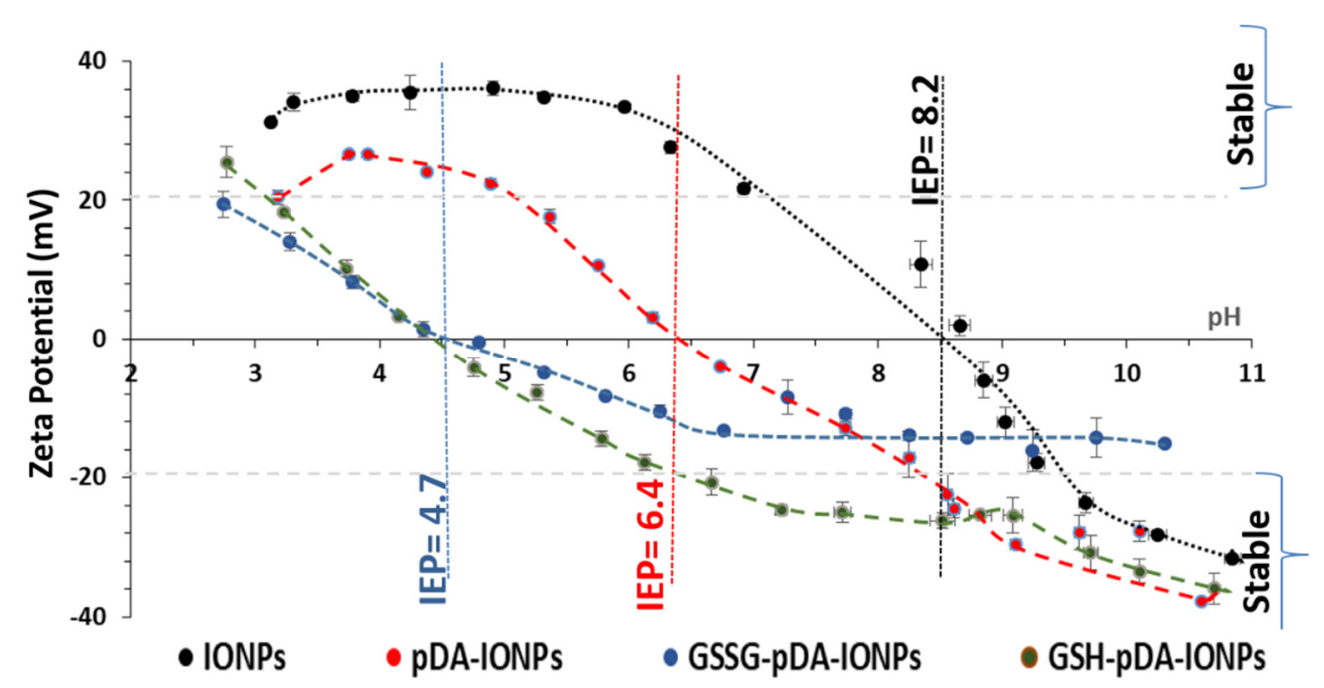

Figure 2. Zeta potential vs $\mathrm{pH}$ curves showing the isoelectric point of differently functionalized nanoparticles in $10^{-2} \mathrm{M} \mathrm{NaCl}$.

The magnetic nature was also analyzed as a calibration curve shown in Figure S4, supporting information (SI) showing the magnetic susceptibility of the prepared IONPs increases with increase in the concentration of nanoparticles used.

Chemical and thermal properties of pDA- and GSSG-functionalized IONPS are further characterized using FTIR, XPS and TGA measurements. The presence of pDA layer is confirmed from IR stretching frequencies at 1611, 1460 and $1270 \mathrm{~cm}^{-1}$, which correspond to the vibration bands of aromatic rings of pDA (Figure 3A) [21]. Naked IONPs exhibit the magnetite characteristic Fe-O stretching band at $580 \mathrm{~cm}^{-1}$, which remains constant even after the formation of a pDA layer on the surface. FTIR spectrum of GSSG-modified pDA-IONPs gives an additional strong stretching band of $\mathrm{C}=\mathrm{O}$ at $1690 \mathrm{~cm}^{-1}$, attributed to the carboxylic group of GSSG, which remains after the reduction of GSSG into GSH (Figure 3B). Furthermore, a broad stretching band of primary amine is observed on GSSG modification at $3300 \mathrm{~cm}^{-1}$, which is shifted to $3400 \mathrm{~cm}^{-1}$ on the reduction step of GSSG to GSH. This shift may be explained by the intramolecular hydrogen bonding between $\mathrm{NH}_{2}$ and carboxylic oxygen. The GSH modified nanoparticles show a slightly quenched fluorescence emission when compared to only pDA-IONPs (Figure 3C), measured at the same concentration, which supports the immobilization step of glutathione onto pDA-IONPs. Indeed, pDA nanoparticles are known to show an inherent fluorescence property [35]. Since pDA possesses reactive quinone and amine groups, it can actively bind to the GSSG molecule and consequently GSH serves as an excellent fluorescent quencher. Thus, GSSG-pDA shows the potential to quench fluorescence via plausible electron-electron transfer energy process [36]. 

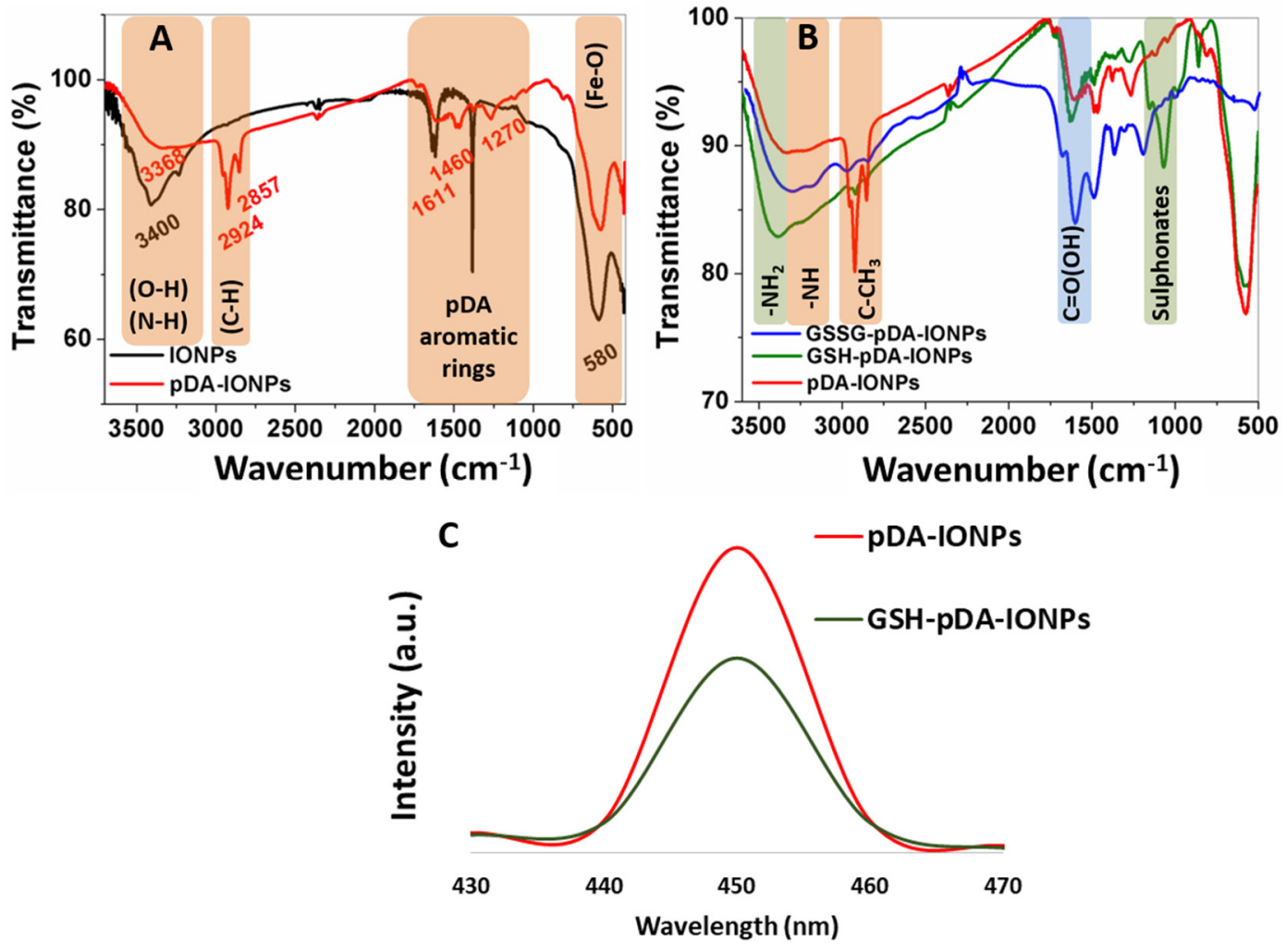

Figure 3. (A,B) Fourier transform infrared (FTIR) spectra showing the successful conjugation of pDA and GSSG molecules on IONPs; and (C) fluorescence spectra of pDA-IONPs and GSH-pDA-IONPs with $\lambda_{\text {excitation }}=400 \mathrm{~nm}, \lambda_{\text {emission }}=450 \mathrm{~nm}$.

X-ray photoelectron spectroscopy is a highly surface sensitive technique and provides accurate information about surface properties [37,38]. The XPS survey scans of IONPs, pDA-IONPs and GSSG-pDA-IONPs are shown in Figure 4. The elemental composition, calculated from XPS (Table 1), explains that after pDA coating, the atomic percentages of carbon and nitrogen increase drastically from $3.0 \%$ to $41.8 \%$ and from $1.1 \%$ to $4.5 \%$, respectively, which confirms the presence of a pDA shell, where Fe atomic percentage decreases. Indeed, as the XPS is a surface analysis technique (about $5 \mathrm{~nm}$ of depth) and the thickness of organic shell increases progressively after each grafting, the inorganic core becomes more and more covered and not easily accessible. On immobilizing GSSG onto pDA-IONPS, the atomic percentage of carbon $(C)$ further increases to $51.1 \%$ and a similar trend is observed for nitrogen. This is also observed on analyzing the survey spectra shown in Figure 4A, where the intensity of carbon and nitrogen increase on reacting IONPs with pDA and GSSG.

To understand the nature of the chemical bonds of Fe and O in bare IONPs, decomposition of XPS spectra was realized. On fitting Fe $2 p$ spectrum, it is split into $2 p_{1 / 2}$ and $2 p_{3 / 2}$ due to spin orbit j-j coupling as shown in Figure 4B [39]. In addition to the two major peaks ( $\mathrm{Fe} 2 \mathrm{p}_{3 / 2}$ at $710.7 \mathrm{eV}$ and $\mathrm{Fe}$ $2 \mathrm{p}_{1 / 2}$ at $724.3 \mathrm{eV}$ ), two satellite peaks are also observed, which are $\mathrm{Fe}(\mathrm{II}) 2 \mathrm{p}_{3 / 2}$ satellite peak at $719.1 \mathrm{eV}$ and $\mathrm{Fe}(\mathrm{III}) 2 \mathrm{p}_{1 / 2}$ satellite peak at $732.7 \mathrm{eV}$ (Figure $4 \mathrm{~B}$ ). The oxidation state of iron species present in the sample may be evaluated thanks to these data. Indeed, the binding energy difference between Fe $2 \mathrm{p}_{3 / 2}$ and its satellite peaks is related to the oxidation state of the iron cations; this difference is close to $6 \mathrm{eV}$ for $\mathrm{Fe}^{2+}$ and $8 \mathrm{eV}$ for $\mathrm{Fe}^{3+}$. In our case, this difference is equal to $8.4 \mathrm{eV}$ for bare IONPs [40]. Thus, XPS shows that the surface of bare IONPs is oxidized with the presence of mainly $\mathrm{Fe}^{3+}$. The other contributions, respectively located at 712.6 and $726.2 \mathrm{eV}$, could not be attributed to $\mathrm{Fe}^{2+}$ contribution, because they should be located at lower energies (about $709 \mathrm{eV}$ ) [41]. However, they may be assigned to Fe-O-OH [42]. Similarly, the XPS spectrum of oxygen in bare IONPs shows two peaks at $530.2 \mathrm{eV}$ 
and $531.6 \mathrm{eV}$, which are attributed to the binding energies of $\mathrm{Fe}-\mathrm{O}-\mathrm{Fe}$ and $\mathrm{Fe}-\mathrm{OH}$ bonds as shown in Figure 4C [43].
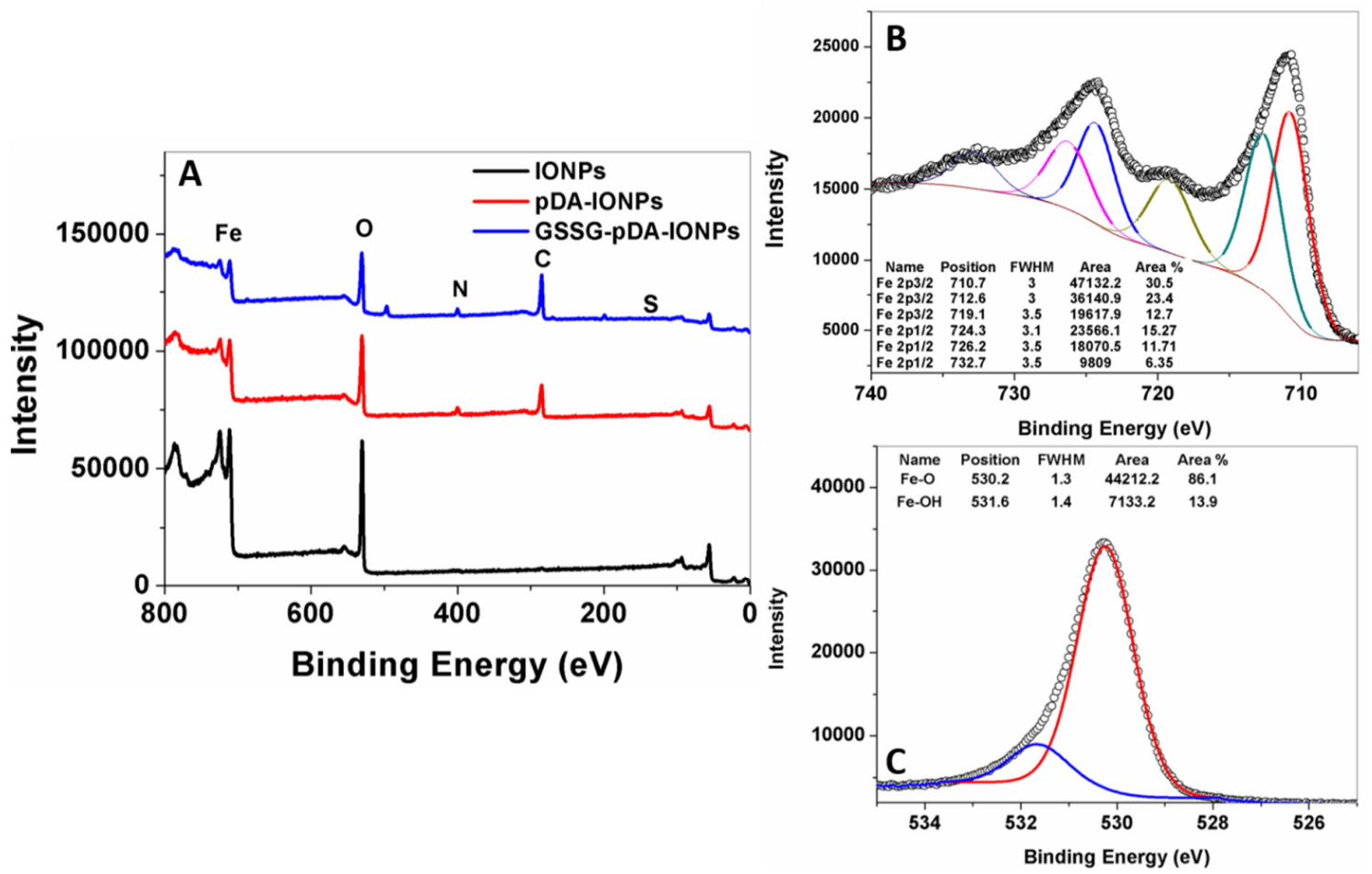

Figure 4. (A) X-ray photoelectron spectroscopy (XPS) survey spectra of the prepared nanoparticles with the fitted peaks of (B) Fe (2p); and (C) oxygen (1s) of bare IONPs.

Table 1. XPS elemental analysis (atomic percentage) of the prepared nanoparticles.

\begin{tabular}{ccccccccc}
\hline Samples & Fe & O & $\mathbf{C}$ & $\mathbf{N}$ & $\mathbf{S}$ & $\mathbf{N} / \mathbf{C}$ & $\mathbf{F e} / \mathbf{O}$ & $\mathbf{F e} / \mathbf{C}$ \\
\hline IONPs & 38 & 57 & 3 & 1 & - & 0.3 & 0.7 & 13 \\
pDA-IONPs & 16 & 37 & 42 & 5 & - & 0.1 & 0.4 & 0.4 \\
GSSG-pDA-IONPs & 9 & 28 & 59 & 3 & 0.1 & 0.1 & 0.3 & 0.2 \\
\hline
\end{tabular}

XPS peak fittings, performed for pDA-IONPs and GSSG-pDA-IONPs, describe the chemical interaction between the grafted molecules as shown in Figure 5. The $C 1$ s peak region is fitted into three components for pDA-IONPs and GSSG-pDA-IONPs (Figure 5A,B). pDA shell on IONPs shows two dominant peaks attributed to $\mathrm{C}-\mathrm{C} / \mathrm{C}-\mathrm{H}$ at $284.8 \mathrm{eV}$ and $\mathrm{C}-\mathrm{N} / \mathrm{C}-\mathrm{O}$ at $286.2 \mathrm{eV}$ of the dopamine polymerized structure and one weak peak attributed to $\mathrm{C}=\mathrm{O}$ at $288.4 \mathrm{eV}$ that corresponds to the possible tautomers of pDA [44].

The incorporation of GSSG into the pDA shell reveals a slight shift in the peak position of $\mathrm{C}-\mathrm{N} / \mathrm{C}-\mathrm{O}$ and $\mathrm{O}-\mathrm{C}=\mathrm{O}$ bonds to 285.8 and $288.1 \mathrm{eV}$, respectively, which suggests the immobilization of GSSG by introducing additional amine and carboxyl functional groups on pDA shell. To ensure the immobilization of GSSG, N (1s) peaks of the functionalized nanoparticles (Figure 5C,D) are fitted into two peaks at $398.4 \mathrm{eV}$ for $=\mathrm{N}-\mathrm{R}$ and at $400.1 \mathrm{eV}$ for $\mathrm{R}-\mathrm{NH}-\mathrm{R}$ that correspond to the tertiary /aromatic and the secondary amines of dopamine intermediate structures [45,46]. The GSSG immobilization displays an additional peak corresponding to $-\mathrm{NH}_{2}$ at $402.1 \mathrm{eV}$, which is attributed to the free amine groups of glutathione structure [44]. Further, the XPS survey scan of GSSG-pDA-IONPs (Figure 4A) shows the presence of sulfur which confirms the immobilization of GSSG onto pDA-IONPs. 

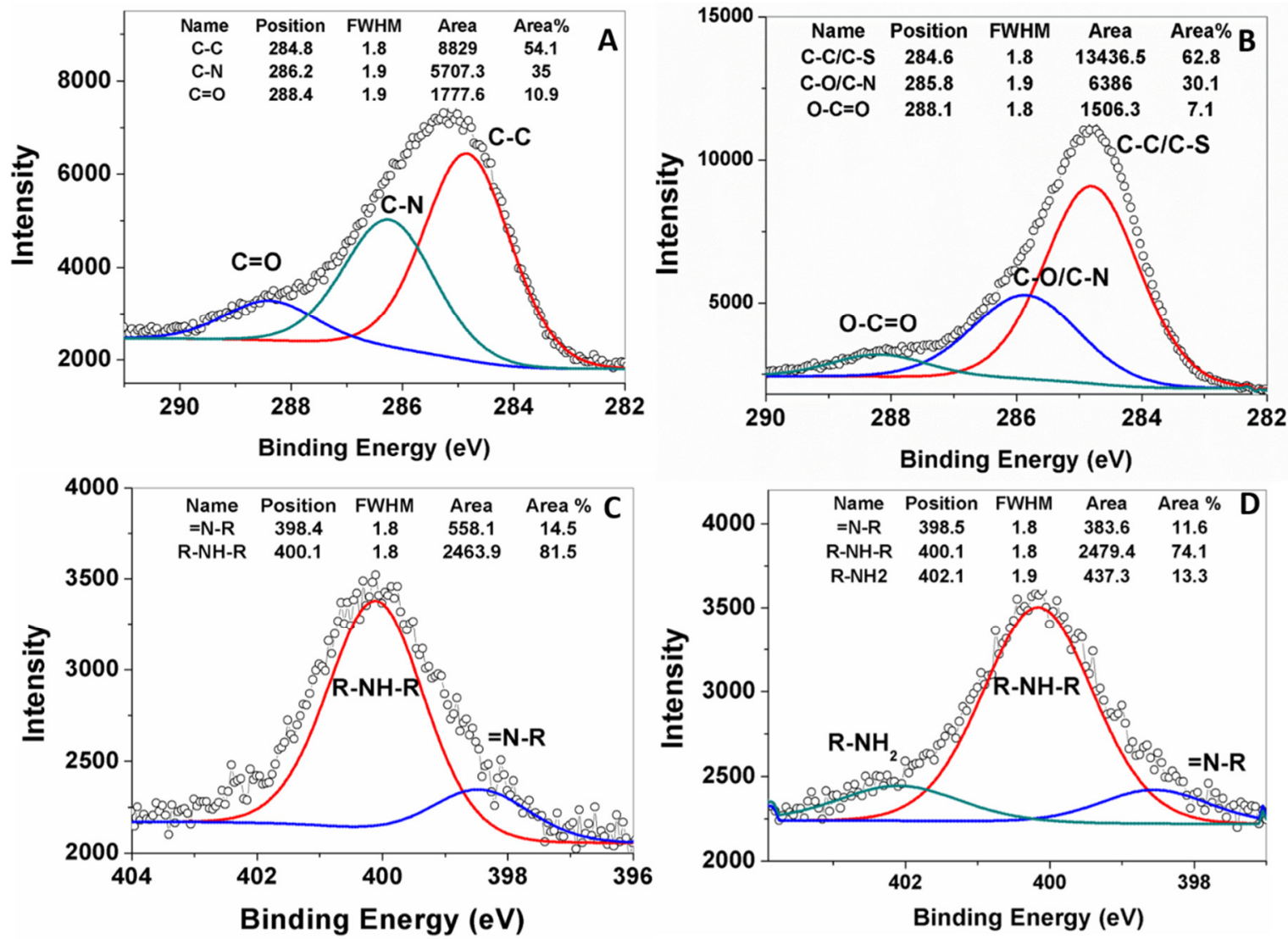

Figure 5. Fitted spectra of C (1s) for (A) pDA-IONPs; (B) GSSG functionalized pDA-IONPs; and of N (1s) for (C) pDA-IONPs; (D) GSSG functionalized pDA-IONPs.

\subsection{Reduction and S-nitrosation of GSSG-pDA-IONPS}

To serve as a dual modality to treat the cancer cells, GSSG-pDA-IONPs were first reduced to GSH using Elman's reagent and then S-nitrosated using sodium nitrite. UV-visible spectra of reduced nanoparticles (Figure 6A), show a sharp shift in the absorbance peak from 325 to $408 \mathrm{~nm}$ on successive addition of GSSG-pDA-IONPs into 5,5-dithiobis-[2-nitrobenzoicacid] (DTNB) which confirms the presence of $-\mathrm{SH}$ in GSH-pDA-IONPs. Indeed, DTNB shows its characteristic absorbance band at $325 \mathrm{~nm}$. When it reacts with the free sulfhydryl group in the reaction mixture, it gives a mixed disulfide or TNB (2-nitro-5-thiobenzoic acid), characterized by the absorbance band at $408 \mathrm{~nm}$, which is in good agreement with the FTIR spectra (Figure 6C). The biological effect of S-nitrosothiol is attributed to the NO release from the breaking of the S-N bond to act as NO donor under physiological conditions. NO formation has the potential to influence the chemotherapy and contribute significantly to cancer biology [47]. Thus, with successive addition of GSH-pDA-IONPs in sodium nitrite solution, the formation of S-nitrosothiols is observed through the appearance of a broad and weak band at $320 \mathrm{~nm}$ (Figure 6B), which is in conformity with the weak absorbance shown by S-nitrosothiols [48].

The FTIR spectrum of GSNO-pDA-IONPs in Figure 6C shows the NO vibration band at $\sim 1500 \mathrm{~cm}^{-1}$ which confirms the presence of S-NO in GSNO-pDA-IONPs. It is also shown that the broad band of GSH-pDA-IONPs, observed due to intramolecular hydrogen bonds, disappears on the formation of the S-NO bond, giving rise to the $\mathrm{N}-\mathrm{H}$ bending band at $3440 \mathrm{~cm}^{-1}$ and suggesting the successful formation of S-nitrosothiols. 

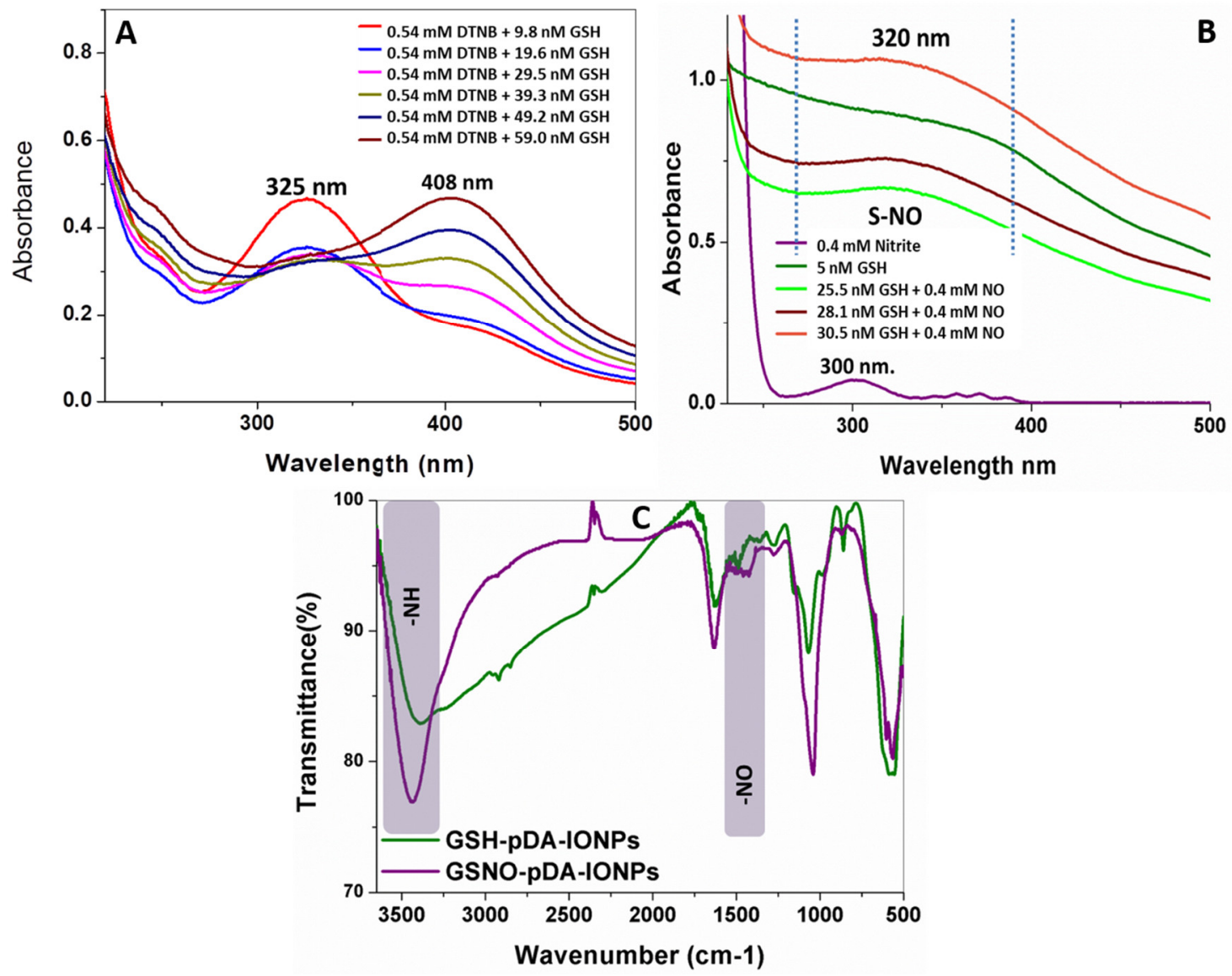

Figure 6. UV-visible spectra showing (A) the reduction of GSSG into GSH-pDA-IONPs; (B) S-nitrosation of GSH-pDA-IONPs; and (C) FTIR spectra of GSNO-pDA-IONPs and GSH-pDA-IONPs.

\subsection{In-Vitro Drug Loading and Release Kinetics}

DTX was first modified with PMPI prior to its loading and was characterized using FTIR and NMR (Figures S5 and S6). The hydroxyl group of DTX reacts with PMPI isocyanate and induces the disappearance of the isocyanate bond (Figure S5) and the formation of $-\mathrm{CN},-\mathrm{NH}$ and $-\mathrm{CONH}$ bonds, which are assigned respectively to 1310,1520 and $1640 \mathrm{~cm}^{-1}$ vibration bands. This confirms the covalent bonding of DTX-PMPI, which was then loaded on GSH-pDA-IONPs. DOX- and DTXloaded nanoparticles were further analyzed using DLS size measurement to ensure the stability of the nanocarrier in the biological medium (RPMI (Roswell Park Memorial Institute medium) and Albumin) at $37^{\circ} \mathrm{C}$ where DTX-modified nanoparticles show an enhanced colloidal stability as compared to DOX-loaded nanoparticles (Figure S7).The PDI values of the nanocarrier dispersed in water were also measured where DOX-loaded nanoparticles had a value of $0.71 \pm 0.24$ and DTX-loaded $0.61 \pm 0.10$.

To evaluate the efficiency of the nanocarriers, it is very important to evaluate the drug loading efficiency of the designed drug delivery system. Since DOX is responsive in UV-vis spectroscopy due to its inherent chromophore, DOX loading and release kinetics were measured using both UV and TG analyses while quantification of loaded DTX was determined using TGA only. A comparative chart (Table S1, SI) shows the loading percentages of DOX and DTX analyzed using UV-vis spectroscopy and the High-performance liquid chromatography (HPLC) method, and observed in the literature.

The surface loading efficiency of DOX, on the developed nanocarrier, is estimated to be $78 \%$ for $24 \mathrm{~h}$ of loading reaction (Figure 7A) using UV-vis absorbance measurement at $490 \mathrm{~nm}$, which is the 
characteristic absorbance band of DOX molecule. The drug loading efficiency was calculated as given in Equation (1) [49].

$$
\% \mathrm{EE}=\frac{\text { Concentration }(\text { Drug added }- \text { Free unentrapped Drug }}{\text { Concentration of Drug Added }} \times 100
$$

Drug release studies were carried out at three different $\mathrm{pH}(3.5,5.4$ and 7.4$)$ with respect to the $\mathrm{pH}$ value of the endocytic compartment, which is lower than that of the normal physiological $\mathrm{pH}$. Figure 7B shows that the release behavior of DOX from the GSH-pDA-IONPs is $\mathrm{pH}$ responsive because of the greater solubility of DOX in acid medium (low $\mathrm{pH}$ ) [50]. This explanation is in good agreement with the results obtained from the zeta potential curves when measured at different $\mathrm{pH}$ (Figure 7C). Indeed, in acid medium, greater solubility and increased hydrophilicity of DOX is obtained due to the protonation of its $-\mathrm{NH}_{2}$ functional group [51]. The rate of DOX release is higher at low $\mathrm{pH}$ (3.5), but when the $\mathrm{pH}$ of the release medium increases to 5.4 and 7.4, the rate of the drug release decreases and the maximum release is observed during the initial $6 \mathrm{~h}$ as shown in Figure 7B.
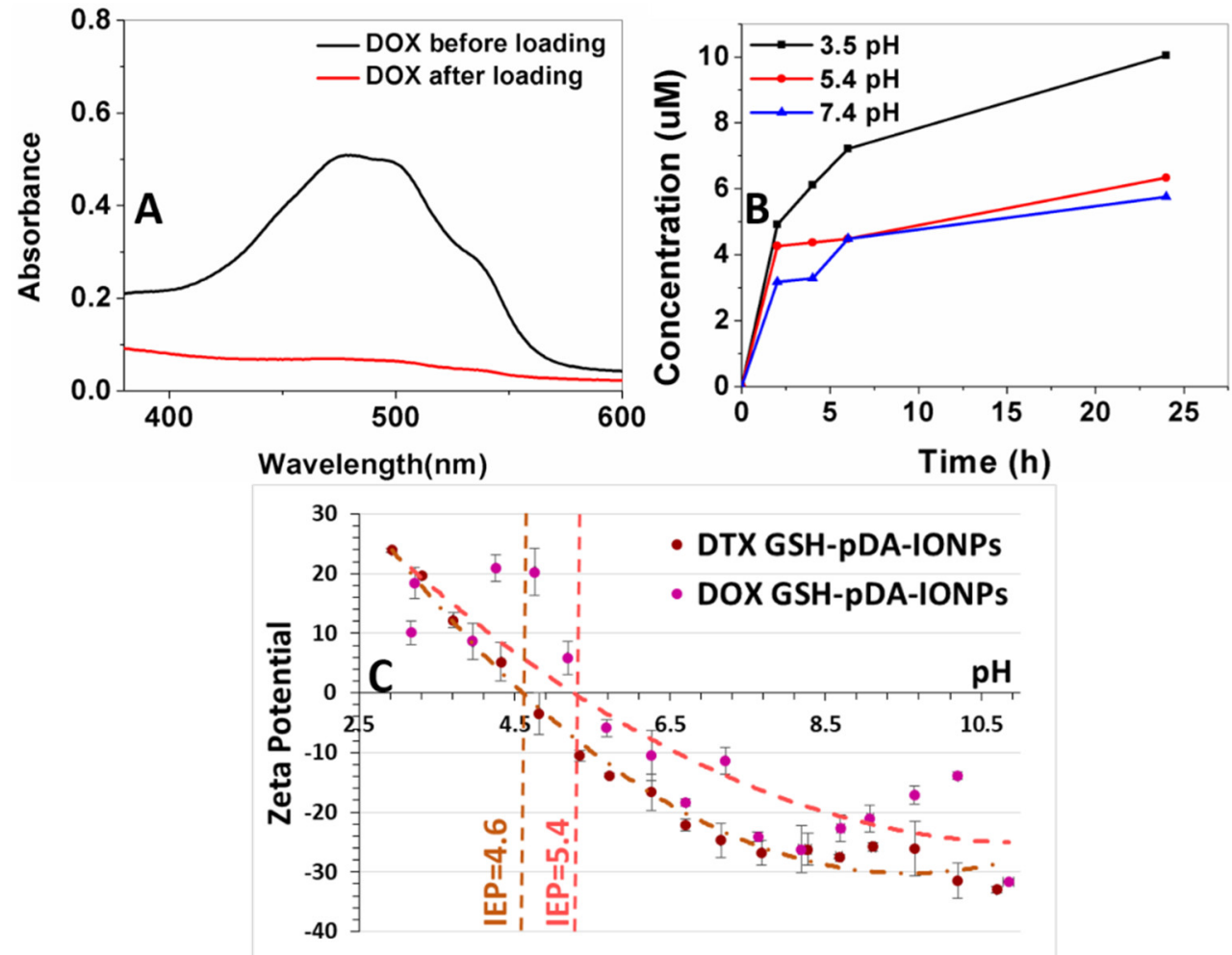

Figure 7. UV-vis absorbance spectra showing (A) doxorubicin loading on GSH-pDA-IONPs; (B) doxorubicin release at different $\mathrm{pH}$ in PBS $(10 \mathrm{mM})$; and (C) zeta potential vs. $\mathrm{pH}$ curves of DOX- and DTX-drug loaded nanoparticles.

Conclusively, moving from $\mathrm{pH} 7.4$ to $\mathrm{pH} 3.5$, the amount of released DOX has doubled. This could be due to the positively charged amine group and its effect on the drug's solubility which depends on its protonation degrees [52]. Moreover, it has also been reported that at low $\mathrm{pH}$ condition, the ionization of the DOX molecule enhances its solubility which leads to an increased diffusion ability, preventing all non-bonding interactions with the polymeric layer of pDA [53]. On comparing the release profile at all $\mathrm{pH}$, two stages of drug release are observed defining the DOX interaction: the first is between 0 and $2 \mathrm{~h}$, where the drug release is fast and can be attributed to the adsorbed drug. The second stage is between 2 and $24 \mathrm{~h}$, where the drug release is slow and could be attributed to the covalently linked drug. As the low $\mathrm{pH}$ favors the protonation of the DOX molecule, so the maximum drug release is observed at $\mathrm{pH} 3.5$. 
Thus, $78 \%$ of DOX loading can result in generating enough concentration of drug within a short span of time, thereby providing a great potential in developing an excellent nanocarrier and a positive approach towards an improved targeted cancer therapy.

TGA measurements (under air flow; nitrogen:oxygen 80:20), on the other hand, support quantifying the drug and immobilization steps. They indicate a weight loss of $6.1 \%$ (Figure 8 ) for bare IONPs, which later helps in the quantification of the organic coating. This weight loss, in the range of 100 to $800{ }^{\circ} \mathrm{C}$, is due to the desorption of the physically adsorbed water and the dehydroxylation of hydroxyl groups on the surface. On heating pDA-IONPs, the weight loss increases to $22 \%$, suggesting the degradation of the polymeric pDA coating on the surface. When GSH is immobilized on pDA-IONPs, the weight loss further increases to $25 \%$, which corresponds to $97.6 \mu \mathrm{mol}$ of GSH/g of IONPs. The amount of the loaded drug on GSH-pDA-IONPs is also calculated using TGA where $13.2 \%$ of weight loss is obtained for DOX and $18.0 \%$ for DTX. Drug-loading efficiency is then estimated to be $243 \mu \mathrm{mol} / \mathrm{g}$ for doxorubicin (DOX) and $223 \mu \mathrm{mol} / \mathrm{g}$ for docetaxel (DTX). The details of the analysis are presented in Table 2.

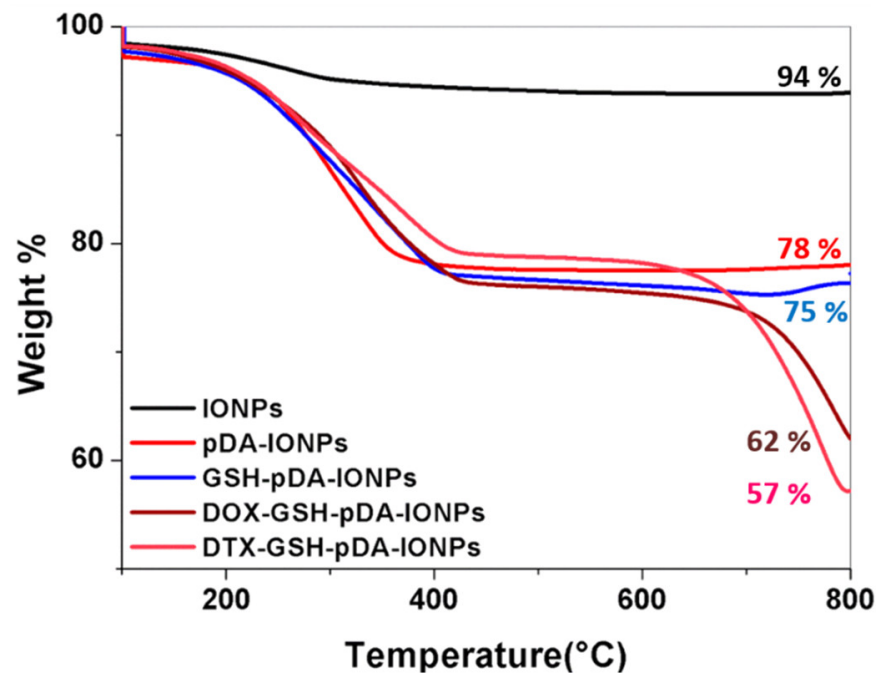

Figure 8. Thermogravimetric analysis (TGA) curves showing the sequential grafting of different organic molecules on the surface of IONPs.

Table 2. Detailed analysis of the weight loss of synthesized nanoparticles and quantification of the grafted molecules.

\begin{tabular}{|c|c|c|c|}
\hline Samples & Weight Loss \% & Amount of Organic Content \% & Amount of DOX/DTX Loaded ( $\mu \mathrm{mol} \mathrm{g}^{-1}$ of IONPs) \\
\hline IONPs & 6 & 0.0 & - \\
\hline pDA-IONPs & 22 & 16 & - \\
\hline GSH-pDA-IONPs & 25 & 19 & - \\
\hline DOX-GSH-pDA-IONPs & 38 & 32 & 243 \\
\hline DTX-GSH-pDA-IONPs & 43 & 37 & 223 \\
\hline
\end{tabular}

\subsection{Cytotoxicity Assay}

In vitro cytotoxicity activity of DOX was assessed using MTS assay against PC 3 cell lines where cells were exposed to the DOX-loaded nanoparticles for $48 \mathrm{~h}$. The results obtained were preliminary but effective to explore the applicability of drug-loaded nanoparticles. Elevated dose studies were done with respect to the concentration of DOX as shown in Figure 9. The IC50 (the half maximal inhibitory concentration) value for DOX was reported to be 334.4-836.1 nM for $48 \mathrm{~h}$ [54,55]. On the other hand, our calculated IC50 value for the free drug is observed at $1,200 \mathrm{nM}$, which is increased to $3,400 \mathrm{nM}$ when loaded on GSH-pDA-IONPs. It is also observed that the free drug is more toxic than the drug-loaded nanoparticles for maximum concentration. Indeed, the percentage of cell survival is $17.2 \pm 4.3 \%$ for free DOX, while DOX-loaded nanoparticles show cell survival of $37.1 \pm 9.5 \%$ in the studied range of concentration. This difference could be explained by the different behavior of the free 
and loaded DOX inside the cells $[56,57]$. DOX shows antiproliferative activity against many tumor cells and has the potential to permeate through the cell membrane very easily thanks to its hydrophobic nature. Unfortunately, DOX alone can also affect the growth of other healthy cells, leading to many side effects. These ultimately result in the depletion of the immune system and the human body becomes more prone to microbial infection, fatigue and, thus, the healing time decreases significantly [58]. Nanocarriers thus come into the role that can be used to target the cancer cells, thereby reducing the side effect of using a drug alone.
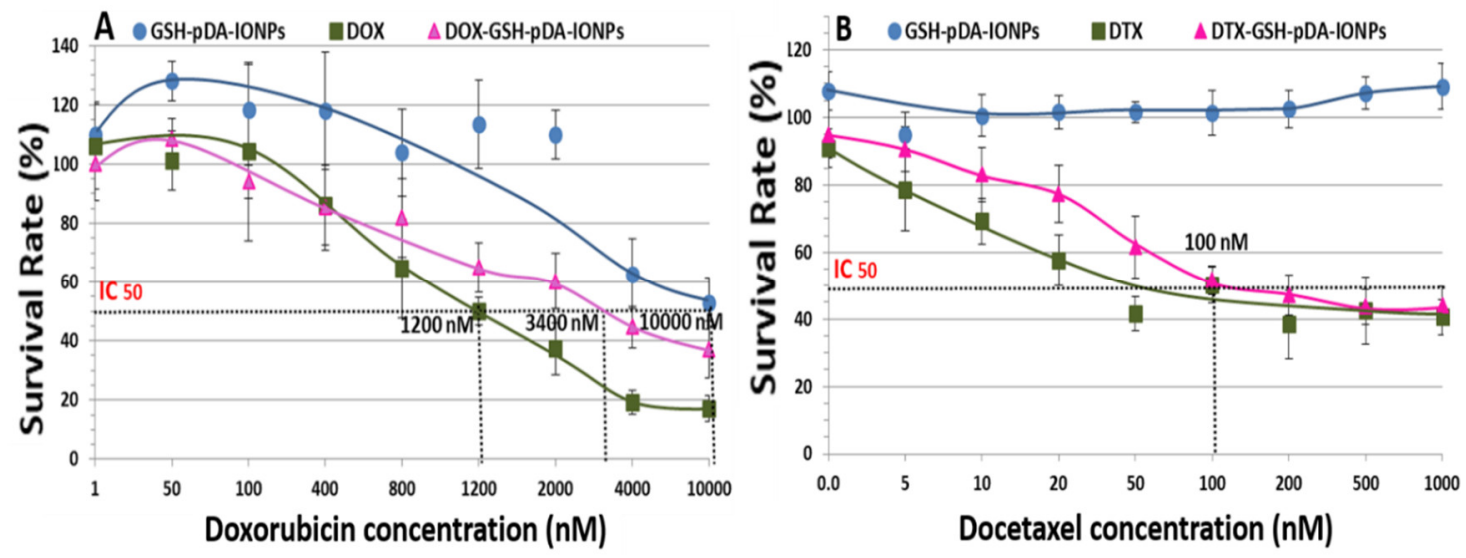

Figure 9. MTS ((3-(4,5-dimethylthiazol-2-yl)-5-(3-carboxymethoxyphenyl)-2-(4-sulfophenyl)-2Htetrazolium)) assay showing the average percent of cell survival against various concentration of (A) DOX; and (B) DTX drug on PC3 cell lines when incubated for $48 \mathrm{~h}$. (Standard deviations were calculated with six measurements).

When MTS assay is performed with the DTX drug, the reported IC50 value is $11 \mathrm{nM} \mathrm{[59].} \mathrm{However,}$ in our case, the IC50 value of the loaded DTX drug increases to $100 \mathrm{nM}$ due to the chemical modification of the molecule. This value is lower than that obtained by Loiseau et al. for DTX-modified titanate nanotubes where the obtained IC50 value was $390 \mathrm{nM}$ [23]. Also, the percentage of surviving cells at a higher concentration is $43.9 \pm 5.7 \%$ for DTX-loaded nanoparticles and $40.5 \pm 5.2 \%$ for free DTX, as shown in Figure 9B. This suggests that it can be used as effective nanocarrier.

The targeting specificity of the developed nanoparticles were further quantified using flow cytometry by an Annexin V-FITC detection kit with PI staining. Necrosis and apoptosis are measured as shown in Figure 10.

At an equivalent drug concentration where the concentration of only GSH-pDA-IONPs in the nanohybrid is in the range of 0.01 to $5.3 \mu \mathrm{g} \mathrm{mL}^{-1}$, it is observed that DOX-loaded nanoparticles reveal a slightly lower antitumor activity compared to free DOX. This may be due to the interaction mechanism of DOX-GSH-pDA-IONPs as it is observed in MTS and confocal studies (Figure S8) [60]. However, in this test, PC-3 cells were exposed to DOX for $24 \mathrm{~h}$, whereas MTS assay cells were exposed for $48 \mathrm{~h}$. On further analyzing the nature of cell apoptosis, it is observed that DOX-loaded nanoparticles show $24.9 \%$ of early apoptotic (Annexin positive / PI negative) for only 24 h of exposure compared to $16.7 \%$ for free drug nanoparticles (GSH-pDA-IONPs). These results suggest that even a small concentration is able to induce cell apoptosis, which confirms the antiproliferative effect of DOX-loaded nanoparticles. 

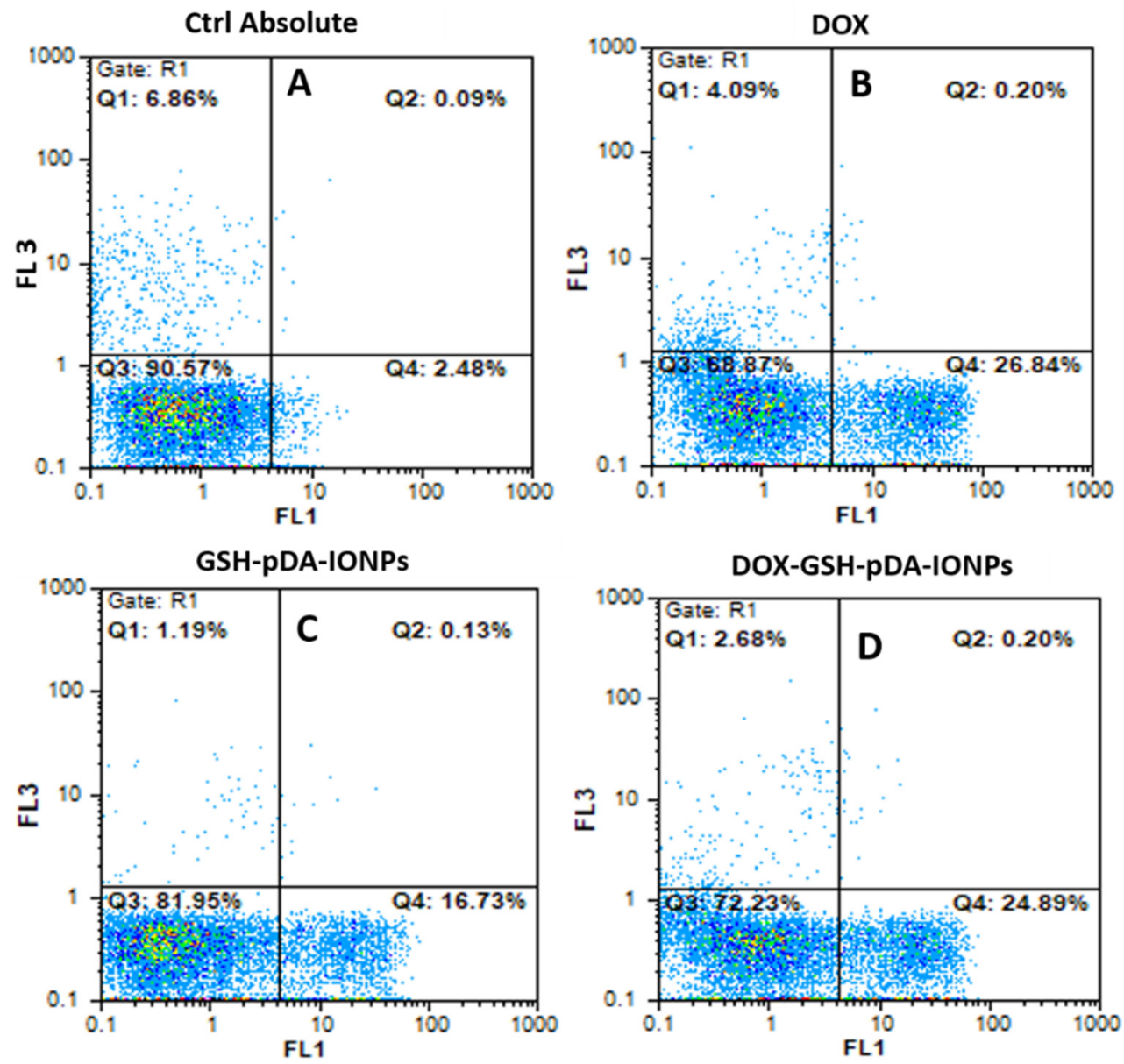

Figure 10. Representative dot plot of Annexin V-FITC/PI ((fluorescein isothiocyanate) detection kit with PI (propidium iodide) staining of PC3 (prostate cancer) cells incubated for $24 \mathrm{~h} \mathrm{~A}$. Without any sample B. with DOX, C. GSH-pDA-IONPs and D. DOX-GSH-pDA-IONPs (flow cytometry: $x$ axis (Fluorescence 1, FL1) Annexin V-FITC and y axis (FL3) propidium iodide). The Q1 quadrant represents unviable cells (PI positive and annexin negative). The Q2 quadrant represents cells that are in late apoptosis or necrosis (both annexin and PI positive). The Q3 quadrant represents viable cells (both annexin-FITC and PI negative). The Q4 quadrant represents cells in early apoptosis (annexin positive and PI negative).

\section{Conclusions}

In this work, we attempted to develop nanocarriers based on IONPs to treat prostate cancer. IONPs were first coated with a biocompatible polymer, $\mathrm{pDA}$, which provides an anchor for further functionalization. Then, glutathione was successfully grafted onto pDA-IONPs in order to increase the efficacy of the developed nanocarrier thanks to its intrinsic biological properties. Before going to the biological assays, the developed nanocarriers were fully characterized using different techniques (TEM, XPS, XRD, TGA, FTIR, UV-vis, DLS and zeta potential measurements) to ensure the successive coating and immobilization of pDA and GSSG onto the IONPs' surface. Two therapeutic molecules were studied in this work: DOX and DTX. These two anticancer drugs have been widely used in the treatment of cancer but they have several side effects when used alone. Thus, to overcome these limitations, we developed nanocarriers that can decrease these side effects. This was preliminarily proved with MTS and apoptosis studies, performed on PC3 cell lines. Drug release studies were also carried out with DOX-loaded nanoparticles to explore the interaction behavior of drugs in physiological and cancerous cell environments (imitated by an acid medium). Subsequently, the GSSG grafted onto pDA-IONPs was reduced to obtain free thiols on the surface, which provides an additional advantage 
to the nanocarrier by forming S-nitrosothiols. This could also be used as a NO donor agent and, thus, proves its worth in cancer treatments.

Supplementary Materials: The following are available online at http:/ www.mdpi.com/2079-4991/9/2/138/s1, Figure S1: XRD pattern of the bare IONPs $(\lambda=1.540598 \AA)$, Figure S2: SAED patterns obtained via TEM analyses of A. bare IONPs and B. pDA-IONPs, Figure S3: Suspension images of (A). pDA-IONPs and (B). GSSG-pDA-IONPs after $24 \mathrm{~h}$ in PBS (10 mM, pH 7.4), Figure S4: Calibration curve showing the magnetic susceptibility vs. concentration of bare IONPs. Measurements were carried out in deionized water at $\mathrm{pH}$ 5.0-6.0, Figure S5: FTIR spectrum of the prepared DTX-PMPI, Figure S6: 1H-NMR predicted spectrum of DTX-PMPI, Figure S7: DLS size measurements to check the colloidal stability of the developed nanoparticles drug loaded FDG (GSH-pDA-SPIONs) in biological media (RPMI and albumin in $\mathrm{NaCl}$ ) at $37^{\circ} \mathrm{C}$, Figure S8: Confocal images of PC3 cell lines with A. no treatment, B. only DOX and C. DOX loaded nanoparticles; Table S1: Comparative chart showing the drug loading efficiencies of doxorubicin and docetaxel, calculated using different method.

Author Contributions: Conceptualization and methodology, N.S., and F.S.; writing-original draft preparation by N.S. writing-review and editing was done by N.M., F.S., R.K. and S.K.S. Under the supervision of N.M. and R.K. Biological experiments were performed by T.N. and C.M.

Funding: This research was funded by the French Government through the CNRS, the "Université de Bourgogne" and the "Conseil Régional de Bourgogne" through the 3MIM integrated project ("Marquage de Molécules par les Métaux pour l'Imagerie Médicale"). This work is also part of the project "Pharmacoimagerie et agents théranostiques", funded by the "Université de Bourgogne" and the "Conseil Régional de Bourgogne" through the "Plan d'Actions Régional pour l'Innovation (PARI)" and the European Union through the PO FEDER-FSE Bourgogne 2014/2020 programs. We would also like to acknowledge DST (YSS/2015/001184) for financial grant in India.

Acknowledgments: The authors would like to thank Julien Boudon and Lionel Maurizi for their help in some experiments, Olivier Heintz for XPS analysis, Rémi Chassagnon for TEM images, Nicolas Geoffroy for XRD pattern, Christine Goze for fluorescence measurements, Véronique Morgand, Christine Arnould, and Gérard Lizard for in vitro investigations.

Conflicts of Interest: The authors declare no conflict of interest.

\section{References}

1. Soppimath, K.S.; Liu, L.-H.; Seow, W.Y.; Liu, S.-Q.; Powel, R.; Chan, P.; Yang, Y.Y. Multifunctional Core/Shell Nanoparticles Self-Assembled from $\mathrm{pH}$-Induced Thermosensitive Polymers for Targeted Intracellular Anticancer Drug Delivery. Adv. Funct. Mater. 2007, 17, 355-362. [CrossRef]

2. Liu, F.; Eisenberg, A. Preparation and $\mathrm{pH}$ Triggered Inversion of Vesicles from Poly(acrylic Acid)-block-Polystyrene-block-Poly(4-vinyl Pyridine). J. Am. Chem. Soc. 2003, 125, 15059-15064. [CrossRef] [PubMed]

3. Liu, J.; Qiao, S.Z.; Hu, Q.H.; Lu, G.Q. Magnetic nanocomposites with mesoporous structures: Synthesis and applications. Small 2011, 7, 425-443. [CrossRef] [PubMed]

4. Lu, A.H.; Salabas, E.L.; Schuth, F. Magnetic nanoparticles: Synthesis, protection, functionalization, and application. Angew. Chem. Int. Ed. 2007, 46, 1222-1244. [CrossRef] [PubMed]

5. Polshettiwar, V.; Luque, R.; Fihri, A.; Zhu, H.; Bouhrara, M.; Basset, J.M. Magnetically recoverable nanocatalysts. Chem. Rev. 2011, 111, 3036-3075. [CrossRef] [PubMed]

6. Lee, D.-E.; Koo, H.; Sun, I.-C.; Ryu, J.H.; Kim, K.; Kwon, I.C. Multifunctional nanoparticles for multimodal imaging and theragnosis. Chem. Soc. Rev. 2012, 41, 2656-2672. [CrossRef] [PubMed]

7. Lee, H.; Dellatore, S.M.; Miller, W.M.; Messersmith, P.B. Mussel-inspired surface chemistry for multifunctional coatings. Science 2007, 318, 426-430. [CrossRef] [PubMed]

8. Liu, N.; Wu, H.; McDowell, M.T.; Yao, Y.; Wang, C.; Cui, Y. A yolk-shell design for stabilized and scalable li-ion battery alloy anodes. Nano Lett. 2012, 12, 3315-3321. [CrossRef]

9. Batul, R.; Tamanna, T.; Khaliq, A.; Yu, A. Recent progress in the biomedical applications of polydopamine nanostructures. Biomater. Sci. 2017, 5, 1204-1229. [CrossRef]

10. Cui, J.; Yan, Y.; Such, G.K.; Liang, K.; Ochs, C.J.; Postma, A.; Caruso, F. Immobilization and intracellular delivery of an anticancer drug using mussel-inspired polydopamine capsules. Biomacromolecules 2012, 13, 2225-2228. [CrossRef]

11. Yi, M.C.; Khosla, C. Thiol-Disulfide exchange reactions in the mammalian extracellular environment. Annu. Rev. Chem. Biomol. Eng. 2016, 7, 197-222. [CrossRef] [PubMed] 
12. Zhang, Z.; Jiao, Y.; Wang, Y.; Zhang, S. Core-shell self-assembly triggered via a thiol-disulfide exchange reaction for reduced glutathione detection and single cells monitoring. Sci. Rep. 2016, 6, 29872. [CrossRef] [PubMed]

13. Ghaz-Jahanian, M.A.; Abbaspour-Aghdam, F.; Anarjan, N.; Berenjian, A.; Jafarizadeh-Malmiri, H. Application of chitosan-based nanocarriers in tumor-targeted drug delivery. Mol. Biotechnol. 2015, 57, 201-218. [CrossRef] [PubMed]

14. Chuang, C.C.; Chang, C.W. Complexation of bioreducible cationic polymers with gold nanoparticles for improving stability in serum and application on nonviral gene delivery. ACS Appl. Mater. Interfaces 2015, 7, 7724-7731. [CrossRef] [PubMed]

15. Israel, L.L.; Lellouche, E.; Ostrovsky, S.; Yarmiayev, V.; Bechor, M.; Michaeli, S.; Lellouche, J.P. Acute in vivo toxicity mitigation of PEI-coated maghemite nanoparticles using controlled oxidation and surface modifications toward siRNA delivery. ACS Appl. Mater. Interfaces 2015, 7, 15240-15255. [CrossRef] [PubMed]

16. Traverso, N.; Ricciarelli, R.; Nitti, M.; Marengo, B.; Furfaro, A.L.; Pronzato, M.A.; Marinari, U.M.; Domenicotti, C. Role of glutathione in cancer progression and chemoresistance. Oxid. Med. Cell. Longev. 2013, 2013, 972913. [CrossRef] [PubMed]

17. Ignarro, L.J. Nitric oxide: A unique endogenous signaling molecule in vascular biology. Biosci. Rep. 1999, 19, 51-71. [CrossRef]

18. Furchgott, R.F. Endothelium-derived relaxing factor: Discovery, early studies, and identification as nitric oxide. Biosci. Rep. 1999, 19, 235-251. [CrossRef]

19. Carlsson, S.; Weitzberg, E.; Wiklund, P.; Lundberg, J.O. Intravesical nitric oxide delivery for prevention of catheter-associated urinary tract infections. Antimicrob. Agents Chemother. 2005, 49, 2352-2355. [CrossRef]

20. Thomsen, L.L.; Miles, D.W.; Happerfield, L.; Bobrow, L.G.; Knowles, R.G.; Moncada, S. Nitric oxide synthase activity in human breast cancer. Br. J. Cancer 1995, 72, 41-44. [CrossRef]

21. Martin, M.; Salazar, P.; Villalonga, R.; Campuzano, S.; Pingarron, J.M.; Gonzalez-Mora, J.L. Preparation of core-shell $\mathrm{Fe}_{3} \mathrm{O}_{4} @$ poly(dopamine) magnetic nanoparticles for biosensor construction. J. Mater. Chem. B 2014, 2, 739-746. [CrossRef]

22. Kläser, K.; Graeser, M.; Steinhagen, D.; Luedtke-Buzug, K. Construction of a device for magnetic separation of superparamagnetic iron oxide nanoparticles. Curr. Dir. Biomed. Eng. 2015, 1, 306-309. [CrossRef]

23. Loiseau, A.; Boudon, J.; Mirjolet, C.; Crehange, G.; Millot, N. Taxane-Grafted Metal-Oxide Nanoparticles as a New Theranostic Tool against Cancer: The Promising Example of Docetaxel-Functionalized Titanate Nanotubes on Prostate Tumors. Adv. Healthc. Mater. 2017, 6, 1700245. [CrossRef] [PubMed]

24. Mirjolet, J.; Barberi-Heyob, M.; Merlin, J.; Marchal, S.; Etienne, M.; Milano, G.; Bey, P. Thymidylate synthase expression and activity: Relation to S-phase parameters and 5-fluorouracil sensitivity. Br. J. Cancer 1998, 78, 62. [CrossRef] [PubMed]

25. Thomas, G.; Demoisson, F.; Boudon, J.; Millot, N. Efficient functionalization of magnetite nanoparticles with phosphonate using a one-step continuous hydrothermal process. Dalton Trans. 2016, 45, 10821-10829. [CrossRef] [PubMed]

26. Millot, N.; Aymes, D.; Bernard, F.; Niepce, J.C.; Traverse, A.; Bourée, F.; Cheng, B.L.; Perriat, P. Particle Size Dependency of Ternary Diagrams at the Nanometer Scale: Evidence of TiO2 Clusters in Fe-Based Spinels. J. Phys. Chem. B 2003, 107, 5740-5750. [CrossRef]

27. Guigue-Millot, N.; Champion, Y.; Hÿtch, M.J.; Bernard, F.; Bégin-Colin, S.; Perriat, P. Chemical Heterogeneities in Nanometric Titanomagnetites Prepared by Soft Chemistry and Studied Ex Situ: Evidence for Fe-Segregation and Oxidation Kinetics. J. Phys. Chem. B 2003, 107, 5740-5750. [CrossRef]

28. Ju, K.-Y.; Lee, Y.; Lee, S.; Park, S.B.; Lee, J.-K. Bioinspired polymerization of dopamine to generate melanin-like nanoparticles having an excellent free-radical-scavenging property. Biomacromolecules 2011, 12, 625-632. [CrossRef]

29. Jiang, J.; Zhu, L.; Zhu, L.; Zhu, B.; Xu, Y. Surface Characteristics of a Self-Polymerized Dopamine Coating Deposited on Hydrophobic Polymer Films. Langmuir 2011, 27, 14180-14187. [CrossRef]

30. Honary, S.; Zahir, F. Effect of zeta potential on the properties of nano-drug delivery systems-a review (Part 2). Trop. J. Pharm. Res. 2013, 12, 265-273.

31. Maurizi, L.; Papa, A.-L.; Dumont, L.; Bouyer, F.; Walker, P.; Vandroux, D.; Millot, N. Influence of surface charge and polymer coating on internalization and biodistribution of polyethylene glycol-modified iron oxide nanoparticles. J. Biomed. Nanotechnol. 2015, 11, 126-136. [CrossRef] [PubMed] 
32. Yu, S.; Chow, G.M. Carboxyl group (-CO2H) functionalized ferrimagnetic iron oxide nanoparticles for potential bio-applications. J. Mater. Chem. 2004, 14, 2781-2786. [CrossRef]

33. Losic, D.; Yu, Y.; Aw, M.S.; Simovic, S.; Thierry, B.; Addai-Mensah, J. Surface functionalisation of diatoms with dopamine modified iron-oxide nanoparticles: Toward magnetically guided drug microcarriers with biologically derived morphologies. Chem. Commun. 2010, 46, 6323-6325. [CrossRef] [PubMed]

34. Sallem, F.; Boudon, J.; Heintz, O.; Séverin, I.; Megriche, A.; Millot, N. Synthesis and characterization of chitosan-coated titanate nanotubes: Towards a new safe nanocarrier. Dalton Trans. 2017, 46, 15386-15398. [CrossRef] [PubMed]

35. Zhang, D.; Wu, M.; Zeng, Y.; Wu, L.; Wang, Q.; Han, X.; Liu, X.; Liu, J. Chlorin e6 Conjugated Poly(dopamine) Nanospheres as PDT/PTT Dual-Modal Therapeutic Agents for Enhanced Cancer Therapy. ACS Appl. Mater. Interfaces 2015, 7, 8176-8187. [CrossRef] [PubMed]

36. Chen, D.; Zhao, L.; Hu, W. Protein immobilization and fluorescence quenching on polydopamine thin films. J. Colloid Interface Sci. 2016, 477, 123-130. [CrossRef]

37. Pauleau, Y. Materials Surface Processing by Directed Energy Techniques; Elsevier: Amsterdam, The Netherlands, 2006.

38. Perriat, P.; Fries, E.; Millot, N.; Domenichini, B. XPS and EELS investigations of chemical homogeneity in nanometer scaled Ti-ferrites obtained by soft chemistry. Solid State Ion. 1999, 117, 175-184. [CrossRef]

39. Petran, A.; Radu, T.; Nan, A.; Olteanu, D.; Filip, A.; Clichici, S.; Baldea, I.; Suciu, M.; Turcu, R. Synthesis, characterization, and cytotoxicity evaluation of high-magnetization multifunctional nanoclusters. J. Nanopart. Res. 2017, 19, 10. [CrossRef]

40. Thomas, G.; Demoisson, F.; Chassagnon, R.; Popova, E.; Millot, N. One-step continuous synthesis of functionalized magnetite nanoflowers. Nanotechnology 2016, 27, 135604. [CrossRef]

41. Yamashita, T.; Hayes, P. Analysis of XPS spectra of $\mathrm{Fe}^{2+}$ and $\mathrm{Fe}^{3+}$ ions in oxide materials. Appl. Surf. Sci. 2008, 254, 2441-2449. [CrossRef]

42. Barr, T.L. An ESCA study of the termination of the passivation of elemental metals. J. Phys. Chem. 1978, 82, 1801-1810. [CrossRef]

43. Martine, M.; Varsha, K.; Christian, R. XPS study of Fe(II)-Fe(III) (oxy)hydroxycarbonate green rust compounds. Surf. Interface Anal. 2008, 40, 323-328.

44. Zangmeister, R.A.; Morris, T.A.; Tarlov, M.J. Characterization of Polydopamine Thin Films Deposited at Short Times by Autoxidation of Dopamine. Langmuir 2013, 29, 8619-8628. [CrossRef] [PubMed]

45. Clark, M.B.; Gardella, J.A.; Schultz, T.M.; Patil, D.G.; Salvati, L. Solid-state analysis of eumelanin biopolymers by electron spectroscopy for chemical analysis. Anal. Chem. 1990, 62, 949-956. [CrossRef]

46. Bernsmann, F.; Ponche, A.; Ringwald, C.; Hemmerlé, J.; Raya, J.; Bechinger, B.; Voegel, J.-C.; Schaaf, P.; Ball, V. Characterization of Dopamine-Melanin Growth on Silicon Oxide. J. Phys. Chem. C 2009, 113, 8234-8242. [CrossRef]

47. Sinha, B.K.; Bhattacharjee, S.; Chatterjee, S.; Jiang, J.; Motten, A.G.; Kumar, A.; Espey, M.G.; Mason, R.P. Role of Nitric Oxide in the Chemistry and Anticancer Activity of Etoposide (VP-16,213). Chem. Res. Toxicol. 2013, 26, 379-387. [CrossRef] [PubMed]

48. Diers, A.R.; Keszler, A.; Hogg, N. Detection of S-nitrosothiols. Biochim. Biophys. Acta 2014, 1840, 892-900. [CrossRef]

49. Awotwe-Otoo, D.; Zidan, A.S.; Rahman, Z.; Habib, M.J. Evaluation of Anticancer Drug-Loaded Nanoparticle Characteristics by Nondestructive Methodologies. AAPS PharmSciTech 2012, 13, 611-622. [CrossRef]

50. Wang, J.; Chen, J.-S.; Zong, J.-Y.; Zhao, D.; Li, F.; Zhuo, R.-X.; Cheng, S.-X. Calcium Carbonate/Carboxymethyl Chitosan Hybrid Microspheres and Nanospheres for Drug Delivery. J. Phys. Chem. C 2010, 114, 18940-18945. [CrossRef]

51. Wu, S.; Zhao, X.; Li, Y.; Du, Q.; Sun, J.; Wang, Y.; Wang, X.; Xia, Y.; Wang, Z.; Xia, L. Adsorption properties of doxorubicin hydrochloride onto graphene oxide: Equilibrium, kinetic and thermodynamic studies. Materials 2013, 6, 2026-2042. [CrossRef]

52. Di Martino, A.; Kucharczyk, P.; Capakova, Z.; Humpolicek, P.; Sedlarik, V. Chitosan-based nanocomplexes for simultaneous loading, burst reduction and controlled release of doxorubicin and 5-fluorouracil. Int. J. Biol. Macromol. 2017, 102, 613-624. [CrossRef] [PubMed]

53. Johnson, R.P.; Jeong, Y.I.; John, J.V.; Chung, C.-W.; Kang, D.H.; Selvaraj, M.; Suh, H.; Kim, I. Dual stimuli-responsive poly ( $N$-isopropylacrylamide)-b-poly (L-histidine) chimeric materials for the controlled delivery of doxorubicin into liver carcinoma. Biomacromolecules 2013, 14, 1434-1443. [CrossRef] [PubMed] 
54. Tanaka, M.; Rosser, C.J.; Grossman, H.B. PTEN gene therapy induces growth inhibition and increases efficacy of chemotherapy in prostate cancer. Cancer Detect. Prev. 2005, 29, 170-174. [CrossRef] [PubMed]

55. Salim, E.I.; Farara, K.; Maria, D. Antitumoral and antioxidant potential of Egyptian propolis against the PC3 prostate cancer cell line. Asian Pac. J. Cancer Prev. 2015, 16, 7641-7651. [CrossRef] [PubMed]

56. Speelmans, G.; Staffhorst, R.W.H.M.; Steenbergen, H.G.; de Kruijff, B. Transport of the anti-cancer drug doxorubicin across cytoplasmic membranes and membranes composed of phospholipids derived from Escherichia coli occurs via a similar mechanism. Biochim. Biophys. Acta Biomembr. 1996, 1284, 240-246. [CrossRef]

57. Nizamov, T.R.; Garanina, A.S.; Grebennikov, I.S.; Zhironkina, O.A.; Strelkova, O.S.; Alieva, I.B.; Kireev, I.I.; Abakumov, M.A.; Savchenko, A.G.; Majouga, A.G. Effect of Iron Oxide Nanoparticle Shape on Doxorubicin Drug Delivery Toward LNCaP and PC-3 Cell Lines. BioNanoScience 2018, 8, 394-406. [CrossRef]

58. Tacar, O.; Sriamornsak, P.; Dass, C.R. Doxorubicin: An update on anticancer molecular action, toxicity and novel drug delivery systems. J. Pharm. Pharmacol. 2013, 65, 157-170. [CrossRef]

59. Ernsting, M.J.; Murakami, M.; Undzys, E.; Aman, A.; Press, B.; Li, S.-D. A docetaxel-carboxymethylcellulose nanoparticle outperforms the approved taxane nanoformulation, Abraxane, in mouse tumor models with significant control of metastases. J. Control. Release 2012, 162, 575-581. [CrossRef]

60. Li, M.; Song, W.; Tang, Z.; Lv, S.; Lin, L.; Sun, H.; Li, Q.; Yang, Y.; Hong, H.; Chen, X. Nanoscaled poly (L-glutamic acid)/doxorubicin-amphiphile complex as $\mathrm{pH}$-responsive drug delivery system for effective treatment of nonsmall cell lung cancer. ACS Appl. Mater. Interfaces 2013, 5, 1781-1792. [CrossRef]

(C) 2019 by the authors. Licensee MDPI, Basel, Switzerland. This article is an open access article distributed under the terms and conditions of the Creative Commons Attribution (CC BY) license (http:/ / creativecommons.org/licenses/by/4.0/). 